\title{
EL DERECHO AL DEBIDO PROCESO EN EL PROCEDIMIENTO ADMINISTRATIVO SANCIONADOR PERUANO EN MATERIA DE DEFENSA DE LA COMPETENCIA ANTE INDECOPI
}

THE RIGHT TO DUE PROCESS ON THE PERUVIAN ADMINISTRATIVE PROCEDURE ON ANTITRUST MATTERS BEFORE INDECOPI

\author{
Francisco Marcos Fernández \\ IE Law School
}

Respect for the principle of "due process" in the administrative procedure envisaged for the application of the prohibitions on anticompetitive behavior established in Peru's antitrust regulations before Indecopi is called into question due to the lack of separation between the investigative body (Technical Secretariat of the Commission of Free Competition) and the decision-making body (Commission of Free Competition).

This article examines the issue from three perspectives. First, from the functional economic perspective, the organization and the administrative sanctioning procedure provided for in the Peruvian antitrust legislation are part of the public enforcement model that entrusts Indecopi (an agency divided into two units) with the enforcement of the prohibitions of anticompetitive conduct. Inevitably, this may lead to a confirmation bias (prosecutorial bias) -conscious or unconscious- of the final decisions adopted by the Commission. Secondly, from the perspective of the right to due process and the principle of impartiality in the European Convention on Human Rights (ECHR), Indecopi's procedure would respect the requirements of the jurisprudence of the European Court of $\mathrm{Hu}$ man Rights (ECtHR). The author proposes that it is convenient to start with a reflection on how the jurisprudence has ruled that the extension of the human rights of the ECHR to legal persons (corporate human rights) should be examined in each case. Thirdly, from the perspective of comparative law, there are competition authorities with administrative procedures and organizations in other countries that have similarities with those followed by Indecopi. In particular, the European Commission and the Italian Autorità Garante de la Concorrenza (AGCM) are briefly mentioned.

KEYWORDS: Due process; administrative procedure; impartiality; sanctioning procedure; competition defense.
Se cuestiona el respeto del principio del "debido proceso" del procedimiento administrativo previsto para la aplicación las prohibiciones de conductas anticompetitivas establecidas en la normativa de defensa de la competencia en el Perú ante Indecopi por la falta de separación entre el órgano instructor (Secretaría Técnica de la Comisión de Libre Competencia) y el órgano decisor (Comisión de Libre Competencia).

El presente artículo examina la cuestión desde tres perspectivas. En primer lugar, desde la perspectiva económico funcional, la organización y el procedimiento administrativo sancionador previstos en la legislación peruana de defensa de la competencia se encuadran en el modelo de aplicación pública que encarga el enforcement de las prohibiciones de conductas anticompetitivas del Indecopi. Inevitablemente, ello puede conducir a un sesgo confirmatorio, consciente o inconsciente, de la decisión final adoptada por la Comisión. En segundo lugar, desde la perspectiva del derecho al debido proceso y el principio de imparcialidad en la Convención Europea de Derechos Humanos (CEDH), el procedimiento de Indecopi respetaría las exigencias de la jurisprudencia del Tribunal Europeo de Derechos Humanos (TEDH). El autor señala que conviene arrancar con la reflexión de que la extensión de los derechos humanos de la CEDH a las personas jurídicas (derechos humanos corporativos) debe ser examinada en cada caso. En tercer lugar, desde la perspectiva del derecho comparado, existen autoridades de defensa de la competencia con procedimientos y organizaciones administrativas en otros países que presentan similitudes con los seguidos por el Indecopi. En particular, se alude concisamente a la Comisión Europea y a la Autorità Garante de la Concorrenza (AGCM) italiana.

PALABRAS CLAVE: Debido proceso; procedimiento administrativo; imparcialidad; procedimiento sancionador; defensa de la competencia.

\footnotetext{
Abogado. Master of Laws (LL.M.) por la University of California, Berkeley, y Doctor en Derecho por la Università degli Studi di Bologna. Profesor en IE Law School (Madrid, España). Contacto: francisco.marcos@ie.edu

Este artículo reproduce las ideas vertidas en un informe emitido a petición del Instituto Nacional de Defensa de la Competencia y de la Propiedad Intelectual (Indecopi). El autor agradece a Indecopi que ha permitido su reelaboración como artículo doctrinal, así como los comentarios de dos revisores anónimos y del Consejo Ejecutivo de THËMIS-Revista de Derecho.

Nota del Editor: El presente artículo fue recibido por el Consejo Ejecutivo de THËMIS-Revista de Derecho el 7 de julio de 2020, y aceptado por el mismo el 9 de octubre de 2020.
} 


\section{INTRODUCCIÓN}

En Perú la aplicación administrativa de las prohibiciones de conductas anticompetitivas prohibidas $^{1}$ es competencia del Instituto Nacional de Defensa de la Competencia y de la Protección de la Propiedad Intelectual (en adelante, Indecopi). Según la regulación vigente, el procedimiento administrativo previsto para la investigación y sanción de que la instrucción del expediente corre a cargo de la Secretaría Técnica de la Comisión de Defensa de la Libre Competencia (en adelante, STCLC), mientras que la eventual declaración de la infracción e imposición de la sanción compete a la Comisión de Defensa de la Libre Competencia (en adelante, $\mathrm{CLC}$ ).

Este artículo argumenta que procedimiento seguido por Indecopi es coherente con el modelo institucional elegido por el legislador peruano para la aplicación de las prohibiciones de conductas anticompetitivas, pues respeta las exigencias del derecho al debido proceso. Las conclusiones que aquí se alcanzan se fundamentan en lo siguiente ${ }^{2}$ :

(i) En un análisis económico-funcional de la singularidad del proceso de aplicación pública de las prohibiciones antitrust que permite explicar el sistema y la organización seguidos por Indecopi, cuyo diseño busca la administración eficiente de los recursos, siendo claro que la organización y el procedimiento de Indecopi no pueden ser infalibles, y que (como ocurre en este tipo de instituciones) puede existir el riesgo de un sesgo confirmatorio o acusatorio en las decisiones de la CLC, se establecen mecanismos varios y suficientes para corregir los errores, también los derivados de ese sesgo (infra apartado §2); (ii) En la conformidad de la organización y procedimientos del Indecopi con las exigencias de la Convención Europea de Derechos Humanos (en adelante, CEDH) según se ha establecido en la jurisprudencia del Tribunal Europeo de Derechos Humanos (en adelante, TEDH) (infra apartado §3); y,

(iii) Finalmente, en el derecho comparado de defensa de la competencia, donde se observa que hay diversas autoridades de defensa de la competencia extranjeras que se organizan y operan de manera similar a como lo hace Indecopi, sin una separación absoluta entre la instrucción y resolución de los expedientes, y respecto de ninguno de ellos se haya concluido que vulneran los principios de debido proceso o las exigencias sobre la imparcialidad del órgano resolutorio (infra apartado §4).

Este análisis comparado se enmarca en la reciente tendencia internacional de alinear los derechos y garantías de defensa de los imputados en los procedimientos sancionadores por defensa de la competencia $^{3}$. La International Competition Network (en adelante, ICN) ha aprobado unos principios comunes sobre esta materia ${ }^{4}$, que han sido suscritos también por el Indecopi ${ }^{5}$. Por tanto, no está de más examinar si el procedimiento administrativo sancionador seguido en el Indecopi y, en particular, si la separación existente entre instrucción y separación de los procedimientos respeta los parámetros exigidos por la jurisprudencia del TEDH ${ }^{6}$. El cumplimiento con los principios y garantías de defensa en los procedimientos sancionadores ante las autoridades de defensa de la competencia es esencial para fortalecer la legitimidad de su misión y dar credibilidad a su contribución al bienestar común (O’Brien, 2018).

Conforme lo señala el Título III del Decreto Supremo 030-2019-PCM que aprueba el Texto Único Ordenado de la Ley de Represión de Conductas Anticompetitivas (LRCA).

2 No se realiza una evaluación con arreglo a la legislación, jurisprudencia y doctrina peruanas, las referencias a las misma se realizan a efectos de contextualizar el examen y las opiniones vertidas aquí. El análisis que aquí se realiza pretende ser más abstracto, pues examina la organización y el procedimiento sancionadores en materia antitrust en el Instituto Nacional de Defensa de la Competencia y de Protección de la Propiedad Intelectual desde una lógica económicofuncional y comparada.

3 Véase Yoo (2019).

4 Desde abril de 2019 la ICN ha establecido unos principios y garantías comunes en los procedimientos de sanción de cárteles que serán de cumplimiento voluntario por las autoridades de competencia que así lo soliciten (con su propio sistema de cooperación, control y revisión), entre los que se encuentran el derecho a que la decisión sea objetiva e imparcial (2019a, pp. 6-7).

5 Indecopi figura entre los suscriptores originarios del documento mencionado en la nota anterior. Véase el ICN (2019b).

6 Sobre la homogeneidad de los derechos fundamentales y las garantías a nivel comparado, véase lo señalado por Waldron: "Ciertamente, las protecciones y garantías no son iguales en todos los países, pero existe una similitud sustancial en los principios a los que se refieren" (2012, p. 32) [traducción libre]. En particular, la jurisprudencia del Tribunal Europeo de Derechos Humanos se encuentra entre ese tipo de normas y principios, a los que se acude por Estados que no son parte (Waldron, 2012, p. 70). El autor (hablando de Nueva Zelanda) subraya el carácter universal de estos derechos y principios (2012, pp. 117-123). 


\section{ANÁLISIS ECONÓMICO Y FUNCIONAL DEL SISTEMA Y LA ORGANIZACIÓN DEL INDE- COPI EN MATERIA DE DEFENSA DE LA COM- PETENCIA}

\section{A. Introducción: la aplicación pública de prohi- biciones de conductas anticompetitivas}

La existencia de autoridades administrativas especializadas en la persecución y castigo de prácticas anticompetitivas de los operadores económicos en el mercado es común a todos los sistemas de defensa de la competencia ${ }^{7}$. Estas instituciones son esenciales para dotar de efectividad a las prohibiciones antitrust (enforcement), pues son las que permiten incrementar la probabilidad de aprehensión, prueba y sanción de los infractores, dotándolas de mayor fuerza disuasoria (Becker, 1968). En efecto, para incrementar la probabilidad de detección ( $y$, en su caso, la posterior convicción y sanción) de las infracciones de las prohibiciones antitrust es esencial crear instituciones especializadas, dotadas de recursos y poderes adecuados y suficientes, y con incentivos para conseguir información sobre las infracciones ${ }^{8}$. La maximización del bienestar social así lo exige ${ }^{9}$.

Las dificultades de obtener y procesar adecuadamente la información que permita detectar y probar la existencia de infracciones de las prohibiciones de defensa de la competencia, junto a la ausencia de incentivos de los particulares para directamente perseguir estas infracciones en los tribunales ordinarios (private enforcement) explican que el recurso a las agencias independientes especializadas en la investigación de conductas anticompetitivas (public enforcement) sea universal en todos los sistemas de defensa de la competencia ${ }^{10}$.
A diferencia de otras normas jurídicas, las prohibiciones antitrust son particularmente complejas y ello dificulta su enforcement. La aplicación de las prohibiciones de conductas anticompetitivas resulta dificultosa por el carácter de estándares legales abiertos que frecuentemente se utilizan en la formulación de estas prohibiciones ${ }^{11}$. Aunque ello dota a estas normas de flexibilidad para hacer frente a las conductas contrarias a la libre competencia, proporcionando gran discrecionalidad en su aplicación ${ }^{12}$, a la vez incrementa la incertidumbre en los operadores sobre si su comportamiento ha incurrido en dichas prohibiciones ${ }^{13}$.

Por ello, la aplicación de las prohibiciones solo es posible tras la obtención y acumulación de prueba de los hechos potencialmente infractores, que suele requerir una intrincada investigación y un profundo análisis para evaluar los potenciales efectos de las conductas en el mercado ${ }^{14}$, conforme a la doctrina jurídico-económica consolidada en la materia, y que sea coherente con la interpretación previa de las prohibiciones en decisiones precedentes de las autoridades de competencia.

El procedimiento administrativo de investigación de las presuntas infracciones busca evitar la arbitrariedad y abusos de las autoridades de defensa de la competencia que impongan castigos sin haber seguido un itinerario reglado en el que se acumule prueba sobre los hechos constitutivos de la infracción y en el que se posibilite la defensa del acusado, con garantías de defensa por su parte.

Dada la imposibilidad de conocer el universo existente en la realidad de conductas anticompetitivas prohibidas por el Título III del Texto Único Ordenado de la Ley de Represión de Conductas Anticom-

El término antitrust se utiliza en este artículo como sinónimo de defensa de la libre competencia, para comprender exclusivamente a las prohibiciones de conductas anticompetitivas y su aplicación en el marco de un procedimiento administrativo sancionador, conforme lo señala el Título III del Texto Único Ordenado de la Ley de Represión de Conductas Anticompetitivas (en adelante, TUO de la LRCA). Se excluyen otras políticas públicas destinadas a la promoción y abogacía de la competencia o el control de concentraciones económicas

8 Son útiles al respecto las observaciones de Shavell (1993, pp. 258-259 y 267-270).

9 Véanse Polinsky y Shavell (2007).

10 Conforme lo señalan Polinsky y Shavell, "usualmente la fuerza pública se favorecerá si es que se requiere de esfuerzos para identificar y castigar a los infractores" (2007, p. 406) [traducción libre]. Véase también Kaply y Shavell (2005).

11 Frente a otras normas jurídicas específicas y precisas, de más fácil aplicación, los estándares legales que configuran las prohibiciones de conductas anticompetitivas reducen los costes de formulación de las normas (véase la amplitud de las prohibiciones establecidas en los arts. 10, 11 y 12 del TUO de la LRCA), pero incrementan los costes de aplicación y la incertidumbre de los operadores sobre la aplicación de las mismas en cada caso. Al respecto, Kaplow (1992).

12 Como lo señala Ottow: "[l]as reglas de competencia son muy flexibles y pueden aplicarse a un amplio rango de situaciones a las que no necesariamente el legislador se anticipó" (2015, p. 30) [traducción libre].

13 Existe un equilibrio entre su precisión y su administrabilidad. Véase Ibáñez (2018, p. 29).

14 Basta pensar en el complejo análisis que puede exigir, en cada caso, la definición del mercado relevante (art. 6. del TUO de la LRCA), la evaluación de los efectos para la aplicación de las prohibiciones relativas del art. 9 TUO de la LRCA, la existencia de posición de dominio de un agente económico (art. 7 del TUO de la LRCA), y no digamos de la apreciación la concurrencia de alguna de las circunstancias que determinan la existencia de infracción, ex. art. 10, 11 o 12, que se tratan de listados meramente abiertos. 
petitivas (en adelante, TUO de la LRCA), es difícil evaluar el rendimiento y la actividad de las autoridades encargadas de aplicarlas (Decreto Supremo 030-2019-PCM, 2019) ${ }^{15}$. No existe un estándar de medida o un punto de referencia (benchmark) objetivos, universalmente aceptados, que le sean exigibles $^{16}$. La verdadera medida de la efectividad de la actividad de investigación y sanción del derecho de defensa de la competencia será el cumplimiento de la ley y la disuasión de la comisión de nuevas infracciones. Y eso es muy difícil de medir (White, 2019; Breit \& Elzinga, 1974, pp. 943-961).

En cualquier caso, en lo que atañe a las decisiones que adopta cualquier autoridad encargada de la aplicación de las normas de defensa de la competencia como Indecopi (excluyendo la posible corrupción, el fraude y otras patologías graves que pudieran afectar al funcionamiento de la autoridad, pero que no se examinan en este artículo, por más que tampoco conste que ninguna de ellas haya afectado en el pasado o afecten en la actualidad a Indecopi) la aspiración principal es minimizar los errores en sus decisiones de aplicación (Ergas, 2009, p. 71). Es decir, desde esta perspectiva se trata de evitar la adopción de decisiones equivocadas en la aplicación de las prohibiciones antitrust (Devlin \& Jacobs, 2010, p. 86).

Una autoridad de defensa de la competencia yerra si declara y castiga infracciones que no lo son (errores tipo 1 o falsos negativos), pero también cuando exonera indebidamente a los infractores (errores tipo 2 o falsos positivos), bien en decisiones explícitas o por actividad insuficiente o tardía (omisión) (Ergas, 2009, p. 72).

Establecer el nivel óptimo de actuación de la autoridad, que excluya los errores y mantenga la fuerza disuasoria de las prohibiciones, es una tarea en la que intervienen distintos factores, relacionados con su organización y diseño, las formas en que la autoridad accede a información sobre posibles vulneraciones de las prohibiciones, las prioridades de la autoridad de competencia, el diseño de sus procedimientos de actuación (investigación y resolución) y la eficiencia y rapidez de sus actuaciones (Ottow, 2015, pp. 87-90).

En cualquier caso, es imposible confiar en la infalibilidad de la aplicación de las prohibiciones por la autoridad de defensa de la competencia. Se producirán errores; por ello, es lógico y natural que en los distintos sistemas de aplicación de estas normas se prevean mecanismos para la posible revisión de sus decisiones en una o diversas instancias, que permitan detectarlos y corregirlos ${ }^{17}$.

Los mecanismos de revisión se muestran principalmente preocupados en la corrección de los errores tipo 1 (escepticismo y sobre aplicación de la prohibición o falso negativo $)^{18}$, lo que conduciría a la revocación y reducción de condenas. En algún caso, la revisión judicial puede también corregir errores tipo 2, cuando se revisan decisiones de las autoridades de aplicación que exoneraban o eximían la aplicación de las normas a determinadas conductas. Pero esto último no es lo más frecuente, pues la principal manera de corregir los errores tipo 2 (credulidad e infra aplicación de la prohibición o falso positivo) es mediante el aumento de los recursos destinados a la detección y prueba de las infracciones, dadas las dificultades normalmente existentes para ello.

De otro lado, desde una perspectiva jurídica se entiende que las agencias de defensa de la competencia desarrollan una actividad de policía administrativa de los mercados, vigilando el comportamiento de los operadores económicos "con el objetivo de asegurar que el proceso competitivo en la realidad se acerque lo máximo posible al modelo teórico de competencia perfecta" (Stucchi López-Raygada \& Ballón Estacio, 2017, pp. 16-18). Siguiendo esta lógica, para dar efectividad a las prohibiciones de prácticas anticompetitivas la legislación peruana prevé que la aplicación administrativa de las normas se realice por el Indecopi (public enforcement)

15 Aunque esto sea una obviedad, es imposible conocer cuál es la ratio óptima de decisiones de aplicación de las prohibiciones de conductas anticompetitivas que deben producirse. Como cualquier otra norma que declara y proscribe conductas ilícitas, no existe un "censo" de infracciones o infractores que perseguir, sancionar o exigir compensación. Esto afecta tanto la aplicación privada como la aplicación pública realizada por autoridades administrativas independientes, como el Indecopi.

16 Es más, no conviene llamarse a engaños, no serán necesariamente mejores las autoridades que incoan un mayor número de expedientes, adopten un mayor número de decisiones, o impongan un mayor número de sanciones. Al respecto, Kovacic et al. subrayan las limitaciones de los métodos basados en el cómputo de expedientes incoados o de decisiones sancionadoras adoptadas por la autoridad (2011, pp. 26-27 y 36-39).

17 Esta taxonomía se explica y describe, últimamente, por Ottow (2015, pp. 88 y 199) y Devlin y Jacobs (2010, pp. 75-132), quienes también argumentan en contra de la preocupación por la sobre-aplicación, falsos negativos o errores tipo 1 de las prohibiciones antitrust).

18 Los sistemas de defensa de la competencia se han preocupado normalmente más por la prevención y corrección de los errores tipo 1. Véanse Devlin y Jacobs (2010, p. 79) y Easterbrook (1984 pp. 3 y 16). Críticamente, véase a Baker (2015, pp. 1-38). 
(Stucchi López-Raygada, 2008, p. 313; Stucchi López-Raygada, 2011, pp. 51-55). Conforme lo señala el TUO de la LRCA, el acceso a la vía jurisdiccional de los perjudicados por esas conductas para la obtención de compensación u otros remedios (private enforcement) solo es posible una vez que Indecopi ha adoptado una decisión y ésta es firme (Decreto Supremo 030-2019-PCM, 2019, art. 54).

La organización, las competencias y los poderes de las agencias especializadas de defensa de la competencia varían en los distintos países (Kovacic \& Hyman, 2012, p. 535). Existe una rica diversidad de los modelos comparados a través de los que se efectúa la aplicación de las prohibiciones antitrust en el interés público a través de procedimientos administrativos sancionadores. Razones de diverso tipo (legales, históricas, sociales, económicas, culturales, etc.) explican la variedad en los diseños seguidos a nivel comparado (Fox, 2010, pp. 473-474).

Finalmente, es importante recordar -como ocurre con otras autoridades de defensa de la competencia- que la función de investigación y sanción de las infracciones de las normas antitrust no es la única que Indecopi posee ${ }^{19}$. Esta función represiva se complementa con otras funciones (asesoramiento y abogacía de la competencia, prevención de infracciones), que coadyuvan al propósito de la salvaguarda de la libre competencia en los mercados y la mejora del bienestar social ${ }^{20}$.

\section{B. Modelo institucional peruano para la apli- cación pública de las prohibiciones de con- ductas anticompetitivas}

La estructura y organización del Indecopi es singular en el panorama institucional comparado ${ }^{21}$. Al margen de que acumule competencias muy dispares junto a las de defensa de la competencia (in- solvencia, propiedad intelectual e industrial, competencia desleal, barreras burocráticas, dumping y subsidios) $)^{22}$, cada una de estas ramas funcionales tienen el apoyo de una rama administrativa común a todas ellas, entre la que se incluye el órgano rector de la institución (Consejo Directivo) ${ }^{23}$.

En particular, en materia de defensa de la competencia, el sistema y la organización institucional peruanas se podría caracterizar como el modelo de agencia administrativa especializada única en el que se separa la investigación y la resolución de los procedimientos sancionadores ${ }^{24}$. En cambio, existen otros países en los que las agencias actúan como acusadoras frente a un juez, que es finalmente quien resuelve e impone la sanción ( $v$. gr., Chile) (Duke, 2015, p. 272). Estos sistemas se conocen como modelos judiciales bifurcados ${ }^{25}$.

La existencia de agencias administrativas únicas en materia de defensa de la competencia es común a nivel comparado y se explica por razones de eficiencia y por la complejidad y las necesidades de especialización técnica que la materia requiere (Duke, 2017, p. 276; Davidson, 2005, p. 105; Diez-Canseco Núñez, 1997, pp. 48-49). Se trata, además, de una opción crecientemente preferida en la organización institucional de los sistemas de defensa de la competencia, con muchos países que las han instaurado en los últimos años ${ }^{26}$. Esta preferencia por los sistemas de aplicación integrados se relaciona también con las particularidades del derecho de la competencia que se construye a base de prohibiciones abiertas y estándares de conducta que son indeterminados o ambiguos (Davidson, 2005, p. 110).

Además, en alguna medida, casi todos los sistemas que encargan la aplicación de las normas antitrust a agencias administrativas únicas contemplan una división del proceso en varias fases u órganos (mo-

19 El diseño y la organización de las autoridades de competencia deben necesariamente tener en cuenta esas facetas no coercitivas de su actividad. Al respecto, véase Ottow (2015, p. 147).

20 Véase Ottow (2015, pp. 25-26 y 30-31).

21 La Organización para la Cooperación y el Desarrollo Económicos (en adelante, OCDE) y el Banco Interamericano de Desarrollo (en adelante, BID) la define como "poco habitual", apuntando al funcionamiento adecuado y a las sinergias de la estructura adoptada (2018, p. 118). Sin embargo, ha sido sido ensalzado ensalzada por los expertos frente al sistema preexistente (Stucchi, 2008, p. 326).

22 La literatura especializada discute la conveniencia de esa acumulación de funciones, pero la evaluación de ese extremo está excluida de este artículo. Véanse Kovacic e Hyman (2012, p. 533; 2013 pp. 9-36), Delgado y Mariscal (2014, pp. 134-159) y Ottow (2015, pp. 130-144).

23 Véase OCDE y BID (2018, p. 27).

24 Al respecto, véase Trebilcock e lacobucci, quienes describen que las posibles fórmulas de organización de las agencias especializadas, dentro de las amplias categorías descritas, son ilimitadas (2002, p. 362). También véase Fox y Trebilcock, que aluden a la debilidad del poder judicial como explicación de la opción por esa alternativa (2012, p. 5).

25 Con respecto al sistema canadiense hasta 1976, véase Trebilcock e lacobucci (2002, pp. 368-372). Asimismo, con respecto al sistema federal norteamericano seguido por el Departamento de Justicia, veáse Ottow (2015, p. 124).

26 Por ejemplo, en Estonia, Francia, Portugal y España. Al respecto, véase Duke (2017, p. 281). 
delos administrativos bifurcados o duales $)^{27}$. Así, aunque en el Indecopi la investigación, acusación y la resolución se concentran en una misma institución, en el procedimiento se separan la instrucción, investigación y la resolución de los expedientes $^{28}$. Con variaciones, este modelo es seguido en Canadá y era el empleado en el Reino Unido hasta la creación de la Competition \& Markets Authority ${ }^{29}$. También es el modelo que se sigue en España en la organización de la Comisión Nacional de los Mercados y de la Competencia.

Por otra parte, el procedimiento administrativo sancionador que sigue Indecopi para aplicar las prohibiciones antitrust se presenta como más largo que el seguido en otras jurisdicciones, contemplando dos instancias administrativas sucesivas ante órganos diferentes (Stucchi López-Raygada, 2008 , p. 325). Aparentemente, el modelo seguido busca garantizar los derechos de los investigados y acusados de vulnerar las prohibiciones y asegurar la solidez de las pruebas que acreditan la realización de la conducta prohibida, permitiendo corregir los eventuales errores en que pudiera incurrir la autoridad ${ }^{30}$.

Como es sabido, la primera instancia tiene lugar a nivel de la Comisión de Defensa de la Libre Competencia (CLC) y, en ella, se distinguen dos etapas, la de fase instrucción/investigación y la fase de resolución. Esta separación es también frecuente en otros procedimientos administrativos sancionadores distintos de la defensa de la competencia (en el Perú y en otros ordenamientos).

En segunda instancia, pero sin salir del procedimiento administrativo, corresponde al Tribunal de Libre Competencia (TLC) resolver sobre los recursos contra las decisiones adoptadas por la CLC (Decreto Supremo 030-2019-PCM, 2019, art.

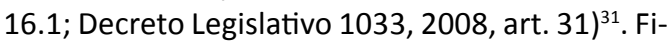
nalmente, contra las resoluciones definitivas del TLC será posible interponer recurso contenciosoadministrativo en la vía jurisdiccional (Decreto Supremo 030-2019-PCM, 2019, art. 44). Con posterioridad al pronunciamiento de la CLC existe pues, otra instancia administrativa de revisión dentro del propio Indecopi y luego el acceso a la vía judicial.

Entre los principios de la potestad administrativa, la legislación peruana reconoce el principio al debido procedimiento. La separación entre instrucción y resolución busca asegurar la imparcialidad y la objetividad del procedimiento, y el respeto y garantía de los derechos de defensa de los investigados (Decreto Supremo 004-2019-JUS, 2019, arts. 248.2 y 254.1 .1$)^{32}$. Ello ha llevado en la práctica a que diversas entidades reguladoras con potestades sancionadoras en el Perú ( $v$. gr., la Superintendencia Nacional de Salud; la Superintendencia de Transporte Terrestre de Personas, Cargas y Mercancías; el Organismo de Evaluación y Fiscalización Ambiental) identifiquen a una unidad como encargada de conducir los procesos de instrucción pero que se encuentre dentro de otra unidad (superior jerárquico) que es la decide y, en su caso, impone las sanciones ${ }^{33}$.

En materia de defensa de la competencia, en Indecopi, la fase de instrucción corre a cargo de la ST$\mathrm{CLC}$, que es un órgano técnico independiente que desarrolla la investigación sobre la posible existencia de infracciones de las prohibiciones de conduc-

27 En referencia a la Comisión Europea y a la estadounidense Federal Trade Commission (en adelante, por sus siglas en inglés, FTC), véase Duke (2017, pp. 273-274) y Trebilcock e lacobucci (2010, pp. 259-461).

28 En el fondo, se podría decir que combina el modelo administrativo integrado y bifurcado como ocurre también, por ejemplo, en la India, Al respecto, véase Fox y Trebilcock (2013, p. 19).

29 Véase a Trebilcock e lacobucci (2002, pp. 372-380)

30 A la vista de lo anterior, la reciente revisión de la OECD y BID recomienda la simplificación y acortamiento del proceso (2018, pp. 130-131). El 21 de junio de 2019 se presentó un Proyecto de Ley que modificaría el Decreto Legislativo 1033, Ley de Organización y Funciones del Indecopi, y el Decreto Legislativo 1034, Ley de Represión de Conductas Anticompetitivas, con la finalidad de que exista una única instancia de resolución de los procedimientos en materia de libre competencia y, de ese modo, agilizar su tramitación.

31 En palabras de Stucchi López-Raygada y Ballón Estacio:

Este esquema procedimental tiene como garantía en favor de los administrados la posibilidad de apelar las decisiones de la primera instancia ante una Sala del Tribunal del Indecopi (conformada por cinco (5) miembros) como segunda instancia revisora (facultad que también le corresponde a la Secretaría Técnica, en caso discrepe del pronunciamiento final de la Comisión). Este Tribunal, en sintonía con el principio de verdad material, cuenta con la facultad de actuar medios probatorios dirigidos a esclarecer los hechos acusados como infracción, de estimarlo necesario (2017, p. 58).

32 En España, la doctrina ha abogado por una interpretación flexible y no rigorista de un precepto muy similar, que impone la separación del órgano acusador y del órgano resolutorio, art. 134.2 de la Ley española 30/1992, de 26 de noviembre, de Régimen Jurídico de las Administraciones Públicas y Procedimiento Administrativo Común. Al respecto, véase López Torralba (2005).

33 Así, por ejemplo, el Organismo de Evaluación y Fiscalización Ambiental (OEFA) quien conduce la instrucción es una subdirección, pero quien aplica la sanción es la dirección de la cual depende, mientras en la Superintendencia Nacional 
tas anticompetitivas establecidas en el Título III del TUO de la LRCA (Decreto Supremo 030-2019-PCM, 2019, art. 15.1). Todo parece indicar que la STCLC es prudente y razonable a la hora de decidir incoar una investigación de una posible infracción de las prohibiciones antitrust (American Bar Association [ABA], 2019, p. 60).

La investigación de la Secretaría finaliza con el informe técnico que concluye la fase de instrucción, en el que la STCLC evalúa la existencia de infracción y da traslado del expediente, junto con las alegaciones de las partes a la Comisión de Defensa de la Libre Competencia (Decreto Supremo 030-2019PCM, 2019, art. 36). A continuación, la fase de resolución se desarrolla ante la CLC, un órgano separado de la STCLC (también independiente ${ }^{34}$ ), que es el encargado de resolver sobre las propuestas de decisión en materia sancionadora que recibe de la STCLC, como lo señala la Ley de Organización y Funciones del Indecopi (Decreto Legislativo 1033, 2008, art. 23).

La concepción de la CLC como un órgano de carácter estrictamente decisorio hace que en la práctica sus miembros desempeñen sus cometidos a tiempo parcial (Decreto Supremo 030-2019-PCM, 2008, art. 21.d) ${ }^{35}$. Esa situación contrasta con la del personal que presta sus servicios en la STCLC, que lo hace a tiempo completo y en régimen de exclusividad $^{36}$. De ahí que, como no existe personal específico de soporte y asistencia para la CLC, la legislación prevea que la STCLC proporcione ese apoyo administrativo (Decreto Supremo 0302019-PCM, 2008, arts. 21.h y 44.1 ).

\section{Posible sesgo confirmatorio en las decisio- nes de la Comisión de Defensa de la Libre Competencia}

Los sistemas de defensa de la competencia consistentes en una agencia administrativa única suelen asegurar un mayor conocimiento o experiencia en sus decisiones y proporcionan una mayor eficiencia administrativa (Trebilcock \& lacobucci, 2010, pp. 463-464; Ottow, 2015, pp. 129-130)37. El ahorro es considerable ${ }^{38}$; no obstante, en el panorama comparado existe una variación notable en el grado de integración o bifurcación/dualidad orgánica que presentan, de modo que en la práctica no existe una separación tajante entre solo dos tipologías de organizaciones, presentándose un continuum en el que son posibles alternativas y combinaciones múltiples.

Precisamente por la integración que subsiste en la organización de los sistemas de agencia administrativa "única", se les censura por apariencia de falta de imparcialidad ${ }^{39}$. En la medida que se combinan las funciones de investigación/instruc-

de Salud quien lleva la investigación es una intendencia, pero quien resuelve e impone las sanciones es una superintendencia adjunta de la cual depende. En la práctica, al parecer, el superior jerárquico suele seguir (copiando en algunos casos) el informe de la autoridad instructora pues las decisiones ya están alineadas y puede incluso ocurrir que la autoridad que decide la aplicación devuelva al instructor para que corrija su propuesta y la envíe de nuevo. Un caso particular presenta el Organismo Superior de Contrataciones con el Estado, pues aquí el propio Tribunal recibe la denuncia evalúa si hay indicios para incoar un procedimiento, lo inicia, requiere información a los investigados y, eventualmente, sanciona (Decreto Supremo 344-2018-EF, 2018, art. 260).

34 Según la Ley de Organización y Funciones del Indecopi, los cuatro integrantes de la CLC son nombrados por el Consejo Directivo de Indecopi entre profesionales "de reconocida solvencia e idoneidad profesional y cinco (5) años de experiencia en temas afines a la materia de competencia de la respectiva Comisión” (Decreto Legislativo 1033, 2008, art. 22.b). En la actualidad estos miembros son Dña. María Pilar Cebrecos González (presidente), D. Dante Mendoza Antonioli, D. Lucio Andrés Sánchez Povis y D. Raúl Lizardo García Carpio y, a primera vista, son todos ellos profesionales con conocimiento y experiencia en materia de defensa de la competencia y regulación. Para mayor información, véase la página web de Indecopi (https:/www./indecopi.gob.pe/web/defensa-de-la-libre-competencia/comisionados - numero_118733).

35 Al respecto, la OCDE y el BID señalan que sus "miembros ejercen sus funciones a tiempo parcial y están escasamente retribuidos" (2018, p. 11), que "desempeñan su función a tiempo parcial" $(2018$, p. 31) y que "[las] funciones escasamente retribuidas que los comisionados y los vocales del Tribunal desempeñan, además, a tiempo parcial” (2018, p. 37). Una de las recomendaciones de la OCDE y el BID es precisamente cambiar la dedicación de los miembros de la Comisión y dotarla de más recursos (2018, pp. 127 y 131).

36 Sobre el particular, la OECD y el BID alertan que dicha "situación excesivamente ventajosa [de la] Secretaria Técnica (cuyos miembros se desempeñan) a tiempo completo, [...] podría dar también lugar a conflictos de intereses y a que se atraigan candidatos menos cualificados de lo que sería deseable" (2018, p. 37).

37 En concreto, Ottow apunta cómo los modelos que establecen separación estricta pueden conducir a costes adicionales, largos procedimientos y menor efectividad en el enforcement de las prohibiciones (2015, pp. 129-130).

38 Según Wils,

ciertamente, un sistema puro en el que una persona o grupo de personas investigue y decida es administrativamente más económico que un segundo sistema donde una persona o grupo investiga y otra persona o grupo decide. En el segundo sistema, la persona o grupo que decida inevitablemente deberá adquirir al menos parte del conocimiento del caso reunido por la persona o grupo que investigue (2004, p. 221) [traducción libre].

39 En palabras de Crane: "Un proceso que depende de una sola entidad para iniciar una investigación, realizar una orden administrativa y revisarla, genera preocupación sobre la independencia del proceso de adjudicación” (2011, pp. 221-222) [traducción libre]. También Ottow señala: 
ción y de resolución/sanción en una misma institución y, al margen de que desde el punto de vista de la organización interna habrá algún tipo de división, se considera que existirá siempre un sesgo acusador o confirmatorio (prosecutorial bias/confirmatorial bias) de la agencia en su conjunto. En efecto, de algún modo se percibe que operan como "jueces de su propia causa" (Fox \& Trebilcock, 2012, p. 7) y eso nublaría la independencia de sus decisiones (nemo judex in re sua decía el Código Justiniano) ${ }^{40}$.

La crítica anterior se formula, por ejemplo, tanto del procedimiento ante la Comisión Europea como del procedimiento ante la autoridad estadounidense, la Federal Trade Commission (Shapiro \& McCarthy, 2011, pp. 4-5; Duke, 2017, p. 464) ${ }^{41}$. La autoridad de defensa de la competencia holandesa (Authority for Consumers \& Markets) o la británica (Competition \& Markets Authority) tampoco establecen una separación formal entre distintas entidades para la investigación, persecución y decisión de las infracciones de las normas antitrust, aunque introducen diversas medidas destinadas a evitar y controlar los posibles sesgos en las decisiones (Ottow, 2015, p. 125). Finalmente, el caso de la Comisión Europea es particularmente ilustrativo a los efectos del presente artículo, pues pueden encontrarse alguna similitud con el procedimiento administrativo ante Indecopi (Trebilcock \& labocucci, 2010, p. 463, §4.1). El mismo equipo de la Dirección General de Competencia (en adelante, DGCOM) asume la tarea de investigar las posibles infracciones $y$, en su caso, declarar la existencia de infracción (OCDE, 2005, p. 62; Forrester, 2009, pp. 836-839). Se prevén mecanismos de control interno para evitar los sesgos ${ }^{42}$, "pero, aunque estos controles internos deban ser bienvenidos y constituyan salvaguardas adicionales, no proporcionan una separación funcional dentro de la Comisión Europea" (Ottow, 2015, p. 127).
Una apreciación análoga, sobre la falta de separación entre la CLC y la STCLC y a la dependencia de la CLC de la STCLC se hace sobre la organización y el procedimiento del Indecopi para la investigación de violación de prohibiciones de conductas anticompetitivas. La STCLC se presenta como el órgano con más recursos, lo que inicialmente supondría una mayor efectividad en la detección e investigación de conductas potencialmente prohibidas. En cambio, la CLC se limita a pronunciarse sobre la propuesta hecha por la STCLC y se apoya en esta última para el desarrollo de sus funciones. Por ello, se critican los amplios poderes de que dispone la STCLC, el desequilibrio de poderes y recursos que existe en comparación con la CLC y la discrecionalidad en el proceso de nombramiento de los directivos de la STCLC ${ }^{43}$.

Al margen de las cuestiones relativas al nombramiento y designación de cargos, que resultan problemáticos y suelen censurarse en casi todos los sistemas ${ }^{44}$, interesa examinar que el evidente desequilibrio de recursos de la STCLC con la CLC, y el apoyo que el primero presta a la segunda, lleve la CLC a caer el sesgo acusador o confirmatorio en la adopción de las decisiones sancionadoras.

Los estudios de psicología cognitiva ponen de relieve lo difícil que puede ser actuar de manera objetiva e independiente en el contexto y circunstancias en las que opera la $\mathrm{CLC}^{45}$. En su proyección sobre el caso concreto supondría el sesgo de la CLC de confirmar las acusaciones y propuestas de la STCLC: "Este sesgo confirmatorio se produce porque los sujetos ignoran todas las pruebas nuevas una vez ya han tomado postura, o porque erróneamente interpretan que las pruebas que contradicen sus pensamientos les soportan" (Cooper \& Kovacic, 2012, p. 47). De hecho, esta crítica se deslizó sutilmente en la revisión inter pares de la Organización para la Coo-

Podría existir una falta de controles y balances en el proceso de toma de decisiones [...] [p]odría también existir un 'sesgo de persecución'; en sus palabras, el equipo que maneje la causa podría poseer una tendencia natural a examinar los hechos de forma que favorezca el hallazgo de una infracción (2015, p. 123) [traducción libre].

40 Como luego veremos, existe una sobrevaloración de esta regla y de sus implicaciones en el diseño de las instituciones. Al respecto, Vermeule sostiene que:

El resultado es que nunca es un argumento constitucional suficiente señalar que una propuesta institución o propuesta interpretación de prácticas o reglas constitucionales ambiguas podrían violar el principio de nemo iudex, o podrían 'poner al zorro a cargo del gallinero'. Uno debe preguntarse si el conflicto es evitable o inevitable; y, en caso fuera evitable, si sería en general bueno o malo evitarlo. En varios casos, las violaciones de nemo iudex son inevitables o afirmativamente deseables (2014, p. 110) [traducción libre].

41 A pesar de que se adoptaron medidas para corregir esos riesgos, véase Fox y Trebilcock (2010, p. 464).

42 Véase Marsden (2009, pp. 24-29).

43 Al respecto, Patrón centra su crítica en la persona individual que asume la dirección de la STCL, aunque para eso subraya su función de apoyo de la CLC, lo que contrasta con la censura que otros hacen de tal extremo (2008, pp. 142-143).

44 Respecto de las autoridades de defensa de la competencia en España, véanse Rallo (2014) y Marcos (2017).

45 Al respecto, véanse Moore et al. (2010) y Nickerson (1998). 
peración y el Desarrollo Económicos y el Banco Interamericano de Desarrollo en $2018^{46}$.

Según este argumento, el procedimiento sancionador de Indecopi no garantizaría adecuadamente los derechos de defensa de los acusados porque existe una posible falta de imparcialidad del órgano decisorio. La aparente falta de independencia de la CLC se cifraría en un sesgo acusatorio y confirmatorio, agravado por la asistencia y apoyo que la STCLC presta a la CLC. A resultas del sesgo, existiría el riesgo de que la CLC se limite a confirmar y seguir las propuestas de la STCLC con demasiada facilidad, adoptándose decisiones erróneas ${ }^{47}$.

En suma y a grosso modo, el problema radicaría en la falta de criterio propio de la CLC que siempre seguiría las propuestas de la STCLC. Aunque no se dispone de una evidencia empírica de este extremo, hay referencias a que la CLC suele seguir las propuestas de la STCLC y otro tanto ocurre después ante la Sala Especializada en Libre Competencia del Tribunal de Indecopi ${ }^{48}$, aunque esto suela ocurrir en todas las agencias de competencia de modelo integrado, siendo excepcionales las decisiones del órgano resolutorio discordantes con la propuesta del órgano instructor.

\section{Prevención y remedios frente a los erro- res de la Comisión de Defensa de la Libre Competencia}

En abstracto, es cierto que podría argumentarse que sería deseable que hubiera una separación mayor entre la STCLC y la CLC, y que la última contase con más recursos y personal de apoyo propio y distinto de la STLC. Pero la realidad no es panglosiana, por los motivos que sean esa no es la situación actual. Este diseño es el resultado de un equilibrio de los recursos y objetivos perseguidos, en el que la imparcialidad decisoria es un valor por tener en cuenta, pero ni la única, ni la más importante (Vermeule, 2014, pp. 107-108).

Aunque la separación entre instrucción y resolución de los procedimientos sancionadores constituye una recomendación estándar de las organizaciones internacionales expertas en esta materia para asegurar la integridad del procedimiento y la imparcialidad de las decisiones (Gómez Apac, 2009, p. 478), en el panorama comparado existen varios modelos en los que esa separación no existe $^{49}$. La explicación es sencilla: responden a diversas alternativas en la organización de las autoridades de competencia, con sus costes y sus beneficios. En efecto, lo que se gana con la separación en términos de integridad se pierde en el aprovechamiento conjunto del conocimiento y de los recursos sobre el expediente objeto de enjuiciamiento ${ }^{50}$.

Por ello, lo mejor es establecer mecanismos preventivos y reactivos para evitar y corregir los errores derivados del sesgo confirmatorio o acusador por la falta de separación ${ }^{51}$.

En principio, parece que la organización actualmente existente en Indecopi responde a las posi-

46 Al respecto, la OCDE y el BID señalan que señalan que "se dice que esta presunta subordinación estaría desdibujando los límites entre las funciones de instrucción y de toma de decisiones" (2018, p. 11) y que "la Comisión de Defensa de la Libre Competencia [...] dependa excesivamente de la Secretaría Técnica" (2018, p. 120. Véase también lo señalado por Stucchi y Ballón (2017, pp. 57-58 y 70).

47 Aunque la crítica se formula respecto de las condenas y multas, con los que se incurriría en errores tipo 1 (falsos negativos), podría predicarse igualmente respecto de los archivos, que supondrían errores tipo 2 (falsos positivos). Véanse supra notas 23 y 26 y texto correspondiente.

48 Según la OCDE y el BID:

Cabe señalar que, de acuerdo con fuentes internas del Indecopi, entre 2015 y 2018 se recurrieron ante el Tribunal sesenta y cinco casos. De estos sesenta y cinco casos, cincuenta y siete fueron confirmados (87,7\%), dos fueron parcialmente confirmados $(3,1 \%)$, en dos de ellos el procedimiento fue sobreseído por pérdida sobrevenida de su objeto $(3,1 \%)$, en uno de ellos la parte apelante desistió $(1,65 \%)$ y solo tres de las resoluciones emitidas por la Comisión fueron revocadas y/o anuladas (4,75\%) y 53 (El porcentaje de éxito del Indecopi ante los órganos jurisdiccionales es del 100\% (2018, p. 32).

Así también, véase Valencia Dongo (2017).

49 En referencia a los sistemas norteamericano, chino y europeo, Yoo et al. señalan:

Las tres jurisdicciones difieren en señalar la extensión a partir de la cual se separan los equipos de investigación y de decisión, a partir de un principio de separación de funciones. Si bien ninguna jurisdicción propone una complete separación del equipo de investigación y decisión, en general los Estados Unidos observan una más estricta separación de funciones que en China o la Unión Europea (2019, p. 62) [traducción libre].

50 Según Vermeule, "la combinación de funciones es necesaria para asegurar decisiones administrativas expertas en una sociedad compleja [...] debido a las compensaciones entre la imparcialidad y la experiencia informada en el estado administrativo, la implementación del nemo iudex promovería la imparcialidad a un precio demasiado alto" (2014, p. 120) [traducción libre].

51 Vermeule sostiene que frente a la prevención ex ante, puede contemplarse la reacción ex post, asumiendo los riesgos (2014, pp. 137-138). 
bilidades y limitaciones prácticas que derivan de la configuración concreta de la CLC. Desde una perspectiva funcional, como ya se ha apuntado antes, todos los modelos disponibles a nivel comparado presentan ventajas e inconvenientes ${ }^{52}$, siendo muchos los que siguen una organización y estructura similar a la Indecopi, incluso los que la han adoptado recientemente ${ }^{53}$.

Naturalmente, todos ellos pueden criticarse por el posible sesgo acusatorio, pero normalmente existen remedios eficaces para evitar la adopción de decisiones erróneas y garantizar los derechos de defensa de los acusados. En primer lugar, en el plano preventivo, hay que pensar en la responsabilidad, legitimidad y transparencia de la CLC, que no es un mero "órgano de paja", aunque presente las lógicas limitaciones de recursos de un órgano que actúa a tiempo parcial. En segundo lugar, en el plano reactivo, incluso si existiera una tendencia confirmatoria excesiva de la CLC, se prevé otra revisión posterior ante la Sala de Libre Competencia del Tribunal de Indecopi y, sobre todo, una judicial en varias instancias ${ }^{54}$.

Vistas así las cosas, ex ante la independencia de criterio y reputación del órgano resolutorio se presenta como garantía de la imparcialidad de su decisión. No conviene olvidar que, al margen de las apariencias, la potestad decisoria en los procedimientos antitrust en Indecopi recae exclusivamente en la CLC y sus integrantes son libres de seguir o no la propuesta de la STCLC. En efecto, la decisión última de los expedientes sancionadores es prerrogativa de la CLC, y sus miembros gozan de independencia y criterio para separarse de la propuesta de la Secretaría, incluso adoptando una decisión diferente. Es obvio que la STCLC tendrá un criterio y presentará una propuesta sobre las conductas imputadas e investigadas, pero presumir que se imponga ese criterio a la CLC significaría ignorar la cualificación y reputación de los integrantes de la CLC. Naturalmente, siempre pueden existir sesgos inconscientes de los miembros de la Comisión e inercia a seguir el criterio de la STCLC, pero ese efecto será inherente a cualquier modelo de agencia administrativa integrada a cargo de la investigación y sanción de las infracciones de la legislación antitrust. Lo más preocupante en estos casos sería la falta de independencia del poder político y no los riesgos derivados de la eventual inercia y endogamia institucional.

Además, incluso si el procedimiento pueda presentarse sesgado a favor de la confirmación de la propuesta de la STCLC, los riesgos y peligros que ese sesgo pueda engendrar se reducirán en la medida que existen otros controles posteriores dentro de Indecopi y un ulterior derecho a una revisión judicial plena e independiente de esas decisiones ${ }^{55}$. Presumiblemente, la revisión judicial de la actividad sancionadora de la administración corregirá los posibles errores, excesos y cualquier sesgo en que se hubiera podido incurrir ${ }^{56}$. El diseño adoptado, con una doble instancia administrativa revisora, permitiría detectar y corregir los eventuales errores tipo 1 (sobre aplicación de las prohibiciones, falsos negativos) que pudieran derivarse de un sesgo confirmatorio de la STCLC ${ }^{57}$.

A diferencia de la tesis que aboga por una mayor separación entre CLC y STCLC, no parece razonable que en la realidad actual de los procedimientos sancionadores de Indecopi la separación entre instrucción y resolución de los procedimientos sancionadores deba conducir necesariamente un "aislamiento" de la instrucción, visto que el órgano resolutorio tiene recursos limitados para examinar y evaluar las conductas investigadas y adoptar una decisión ${ }^{58}$. Esta limitación de recursos será particularmente acuciante en los expedientes complejos, con múltiples partes y conductas enjuiciadas, y en

52 Según Komesar, las desventajas son de índole organizativo y de información, y varían en cada modelo (1997, p. 8).

53 Las ventajas en términos de eficiencia y especialización técnica son elevadas, y, por ello, se suele recomendar su adopción en los sistemas de defensa de la competencia de reciente adopción y en economías menos desarrolladas (Trebilcock \& lacobucci, 2010, p. 470)

54 Existe una plena competencia del Poder Judicial para revisar las decisiones administrativas de Indecopi (en los hechos y en el derecho), aunque el porcentaje de confirmación también sea muy elevado (100\%). Al respecto, véase lo señalado por la OCDE y el BID (2018, p. 79).

55 Véanse Duke (2017, p. 278) y Ottow (2015, p. 198).

56 En comparación al modelo vigente en Estados Unidos,

nuestro Derecho se basa en la imposición de sanciones administrativas, que son menos gravosas que las penales (si las compramos con las penas privativas de libertad) y que, aunque llegan teóricamente pronto (frente a la lentitud de los procesos penales), están sometidas al "partido de vuelta" del contencioso-administrativo en el que se pierde la inicial ventaja temporal" (Huergo, 2019, p. 526).

57 Sobre la relevancia de la revisión para corregir errores de las autoridades de competencia, véase OCDE (2018, p. 6) .

58 Según Vermeule, "en algunos arreglos, el sesgo de los tomadores de decisión puede reducirse solo si se reduce la información que mantienen o sobre las cuales mantienen incentivos para invertir al adquirir nueva información" (2014, p. 117) [traducción libre]. 
los que el conocimiento y experiencia del órgano instructor en el caso pueden ser muy valiosos para el órgano resolutorio ${ }^{59}$. Parece lógico que, en tales circunstancias, se contemple la asistencia y el apoyo del órgano instructor y de investigación en la adopción de una decisión sobre el asunto (máxime si existe transparencia plena sobre este extremo, incorporándose al expediente las actas de las reuniones mantenidas entre la CLC y la STLC).

En suma, incluso en aquellas agencias administrativas integradas en las que el órgano de resolución gozase de recursos y medios suficientes para actuar de manera completamente autónoma, carecería de sentido abogar por el "autismo" institucional del órgano resolutorio ${ }^{60}$. La independencia de criterio del órgano resolutorio existirá al margen de los contactos y relaciones que eventualmente tenga con el órgano de instrucción. En todo caso, la revisión por la Sala de Libre Competencia del Tribunal de Indecopi y el recurso a la jurisdicción contencioso administrativa contra las condenas erróneas por Indecopi se presenta como una solución eficiente y de uso generalizado en el derecho comparado para corregir los posibles errores y excesos de la autoridad por falta de imparcialidad ${ }^{61}$. Esta es su principal justificación social ${ }^{62}$.

Finalmente, no puede olvidarse la credibilidad y reputación de Indecopi como una institución eficaz y respetuosa de los procedimientos de defensa de la competencia ${ }^{63}$. Hace unos meses, en su sección dedicada al Derecho de la Competencia, la American Bar Association valoró muy positivamente los procedimientos de Indecopi de acuerdo con los principios de transparencia procedimental (que la adoptó en 2015), concluyendo:

Aunque los criterios aplicados y/o la aproximación de la autoridad pueda variar en cada caso dependiendo de sus particulares circunstancias y aspectos, Indecopi es generalmente reconocida como una entidad seria, que desarrolla sus funciones de acuerdo con su regulación y se compone de personal competente y con buena formación (2019, p. 60).

\section{CONFORMIDAD DE LA ORGANIZACIÓN Y DEL PROCEDIMIENTO SANCIONADOR DE DEFENSA DE LA COMPETENCIA DEL INDE- COPI CON EL ARTÍCULO 6 DE LA CONVEN- CIÓN EUROPEA DE DERECHOS HUMANOS}

\section{A. Introducción}

El principio de imparcialidad y la separación de instrucción y resolución de los procedimientos administrativos sancionadores en el Indecopi se conecta con el derecho a un proceso debido o a un proceso equitativo (due process). El derecho a un proceso debido o justo se reconoce y es común a otros ordenamientos, incluida la Constitución peruana (Const., 1993, arts. 2.24 y 3$)^{64}$.

Aunque obviamente la Convención Europea de Derechos Humanos no es aplicable en el Perú, la jurisprudencia del Tribunal Europeo de Derechos Humanos interpretando el artículo 6.1 de la CEDH es muy elaborada y, por ello, son frecuentes las referencias a la misma, incluso al margen de su falta

59 Sobre el valor de la información y el eventual sacrificio de la imparcialidad, véase Komesar (2010, pp. 446 y 448).

60 Esta previsión suele existir en otros ordenamientos. Véase, por ejemplo, en España al artículo 34. 3 de la Ley 15/2007, de 3 de julio, de Defensa de la Competencia. Reformulado en el artículo 20.8 de la Ley 3/2013, de 4 de junio, de creación de la Comisión Nacional de los Mercados y la Competencia, esta disposición permite que el órgano resolutorio (el equivalente a la CLC) inste al órgano instructor (el equivalente a la STLC) a investigar determinados hechos susceptibles de constituir una vulneración de las prohibiciones de conductas anticompetitivas. Al respecto, véase Gómez Apac (2009, p. 478).

61 También Ottow alude a la revisión judicial como clave en el control del desempeño de las autoridades de competencia, aunque su discusión, como luego veremos infra apartado §3.5, se centre más en la intensidad y profundidad de la intervención y control judicial (2015, pp. 197 y 217-224).

62 Mutatis mutandi vale la argumentación sobre la revisión judicial en sede de apelación de Shavell, que expresamente la extiende al ámbito contencioso-administrativo y construye su argumentación partiendo de que este mecanismo es la receta preferible para la corrección de errores frente a la reforma del procedimiento para introducir cambios que mejoren la calidad de las decisiones (su precisión y exactitud) y reduzcan los posibles errores (1995, p. 380).

63 Prueba de lo anterior es la buena posición que Indecopi alcanza en los rankings elaborados por la American Bar Association, siendo la única nota negativa referida a la duración excesiva de los procedimientos (2019, pp. 142-147).

Véase también lo indicado por Stucchi López-Raygada:

Indecopi ha consolidado una experiencia institucional y funcional en la esforzada labor de defender los derechos e intereses de los consumidores, garantizar el adecuado funcionamiento del proceso competitivo en el mercado y proteger los derechos de propiedad intelectual en todas sus manifestaciones. Desde esta consideración, el Indecopi, en el contexto actual, es una institución confiable, con trayectoria técnica y que ha desarrollado un progresivo proceso de desconcentración a nivel nacional (2011, p. 58).

64 El artículo 139 de la Constitución recoge, además, el principio del debido proceso (139.3) y el derecho de defensa (139.14) en el desarrollo de la función jurisdiccional. 
de aplicación en otras jurisdicciones ${ }^{65}$. Según el artículo 6.1 de la $\mathrm{CEDH}^{66}$ :

Toda persona tiene derecho a que su causa sea oída equitativa, públicamente y dentro de un plazo razonable, por un Tribunal independiente e imparcial, establecido por la Ley, que decidirá los litigios sobre sus derechos y obligaciones de carácter civil o sobre el fundamento de cualquier acusación en materia penal dirigida contra ella.

Para evaluar la conformidad del procedimiento sancionador de Indecopi con el artículo 6.1 de la CEDH es oportuno examinar la fundamentación del derecho a un proceso debido en los procedimientos administrativos sancionadores (como el de defensa de la competencia) que ha realizado la jurisprudencia del TEDH. Esa construcción arranca como una extensión de su aplicación procedimientos penales, con las limitaciones que el propio TEDH ha establecido. Solo si se tienen en cuenta las limitaciones en la extensión del derecho a un debido proceso a los procedimientos administrativos sancionadores se puede evaluar la compatibilidad con la jurisprudencia del TEDH del procedimiento sancionador en materia de defensa de la competencia de Indecopi. De hecho, son ya varias las sentencias del TEDH que se pronuncian específicamente sobre las exigencias concretas y la adaptación de la aplicación del artículo 6 de la CEDH a los procedimientos sancionadores en materia de defensa de la competencia (infra apartado §3.3).

Además, como se analizará a continuación, el TEDH ha restringido notablemente el alcance de los derechos reconocidos en la CEDH a las personas jurídicas (infra apartado §3.2). La práctica totalidad de los sujetos investigados y sancionados por Indecopi suelen ser empresas y operadores económicos que tienen la forma de sociedad mercantil. La jurisprudencia del TEDH ha modulado la extensión de los derechos reconocidos en la CEDH a las personas jurídicas (derechos humanos corporativos) y eso debe afectar también a las diversas garantías comprendidas en el derecho al debido proceso establecido en el art. 6.1 de la CEDH.

Finalmente, y en lo que más interesa a los efectos de este artículo, el TEDH ya ha dictaminado específicamente sobre las exigencias del principio de imparcialidad en los procedimientos administrativos sancionadores por vulneración de las normas de defensa de la competencia y, en concreto, sobre la separación de instrucción y resolución de los expedientes que se tramitan ante autoridades de defensa de la competencia (infra apartado § 3.4).

Como se verá, y esta conclusión es coherente con la que se alcanza desde la perspectiva económico funcional (supra apartado §2), el TEDH ha dictaminado que cuando en las autoridades administrativas de defensa de la competencia no exista separación entre la investigación e instrucción del expediente y la resolución del mismo (y la eventual imposición de sanciones), la posible falta de imparcialidad del órgano decisor no infringirá el derecho a un debido proceso - ex art. 6 de la CEDHsi existe una ulterior instancia de revisión judicial que pueda pronunciarse tanto sobre los hechos como sobre el derecho (A Menarini Diagnostics $S R L$ c. Italia, 2011) ${ }^{67}$. Lo relevante para satisfacer las exigencias del derecho a un debido proceso ex art. 6.1 CEDH es que las decisiones de la autoridad sancionadora sean susceptibles de recurso ante un órgano judicial con plena jurisdicción para revisar tanto las cuestiones de hecho como de derecho (infra apartado $§ 3.5)^{68}$.

\section{B. Los derechos humanos en los procedi- mientos sancionadores de defensa de la competencia}

El reconocimiento de estos derechos de defensa y a un proceso debido protege la debilidad y vulnerabilidad de los individuos en los procesos penales y litigios sobre derechos y obligaciones civiles ${ }^{69}$.

65 A partir del conocido aforismo de Gayo en sus Instituciones "omnes populi, qui legibus et moribus regentur, partim suo propprio, partim communi ómnium hominum jure utuntur", véase el interesante estudio de Waldron (2012, pp. 3-4 y 20). Aunque centrado en el Derecho estadounidense, se refiere a la oportunidad y utilidad de las referencias e invocaciones a tradiciones jurídicas comparadas y al peso de su invocación en contenciosos puramente domésticos

66 Se maneja el texto del Convenio para la Protección de los Derechos Humanos y de las Libertades Fundamentales hecho en Roma el 5 de noviembre de 1950, enmendado por varios protocolos posteriormente, que fue firmado por España el 24 de noviembre de 1977.

67 Moreno Trapiella expresamente distingue la sentencia recaída en el caso De Cubber c. Bélgica, relativa a un proceso penal y en el que el cumplimiento del art. $6 \mathrm{CEDH}$ es necesario desde la primera instancia judicial, de los procedimientos administrativos, en que ello no es preciso siempre y cuando exista una ulterior revisión judicial con plena jurisdicción (Sentencia 9186/80, 1984).

68 Además, ese derecho figuraba ya en el artículo 14.5 del Pacto Internacional de Derechos Civiles y Políticos.

69 Véase el artículo 10 de la Declaración Universal de los Derechos Humanos. Igualmente, véase el artículo 14 del Pacto Internacional de Derechos Civiles y Políticos. En el Perú, el derecho al debido proceso y el principio de imparcialidad se reconocen también en el artículo 8.1 de la Convención Americana de Derechos Humanos. 
El artículo 6 de la CEDH establece el conjunto de derechos y garantías procedimentales que aseguran la integridad del proceso en todas sus fases (instrucción y resolución), incluyendo los estándares de prueba y de revisión de las posibles sanciones ${ }^{70}$.

La jurisprudencia del TEDH ha extendido progresivamente algunas de las garantías a un proceso equitativo establecidas en el art 6.1 del CEDH a muchos procedimientos administrativos sancionadores. La prolongación de las exigencias de los procesos penales a los procedimientos administrativos se fundamenta en la naturaleza represiva y preventiva de algunas sanciones administrativas, que se dirigen al conjunto de la población (a diferencia, v. gr., de las sanciones disciplinarias) ${ }^{71}$. Esa extensión es coherente con la unidad ontológica de los poderes represivos y punitivos del Estado (sean penales o administrativos) (Nieto, 2012, pp. 125-127), que exige el cumplimiento de ciertas garantías para acreditar la concurrencia de los elementos objetivos y subjetivos de la infracción y la eventual imposición de una sanción.

No obstante, no se trata de que todas las garantías del proceso penal se trasladen al procedimiento administrativo sancionador ${ }^{72}$. La exigencia de imparcialidad e independencia del órgano que resuelve el procedimiento y la separación entre instrucción y resolución es precisamente una de las garantías cuyo trasplante al procedimiento administrativo se modula, atendiendo a las exigencias de eficiencia administrativa (Suay Rincón, 1990, pp. 167-171).

En particular, desde la sentencia del TEDH recaída en el caso Société Stenuit c. Francia (Sentencia $11598 / 85,1992)$ las garantías y exigencias del derecho al debido proceso (Convención Europea de Derechos Humanos, art. 6.1.) y las limitaciones a las acciones de los poderes públicos se extienden también a los procedimientos sancionadores en materia de defensa de la competencia. Aunque no se trata de procesos de naturaleza penal (sin que en ellos se prevean las sanciones típicas de priva- ción de libertad), dada la gravedad de las sanciones y el elevado importe que pueden alcanzar las multas de las autoridades de defensa de la competencia, el TEDH ha entendido que las garantías del proceso debido deben extenderse de algún modo también a los procedimientos sancionadores de defensa de la competencia.

Sin embargo, la extensión por el TEDH del ámbito de protección del derecho al debido proceso a los procedimientos administrativos sancionadores se ha realizado de manera flexible según la gravedad de la sanción que podría imponerse al imputado y de cómo afectase a la situación del individuo ${ }^{73}$. Aunque no puede negarse el carácter sancionador de las multas por infracciones de las prohibiciones de conductas anticompetitivas, la extensión de las garantías del debido proceso al procedimiento administrativo sancionador debe tener en cuenta el contexto y las circunstancias del procedimiento en cuya aplicación tiene lugar (Andreangeli, 2012, p. 25). En efecto, el TEDH ha progresivamente ensanchado la protección del debido proceso a los procedimientos sancionadores considerados de naturaleza cuasipenal (Jussilla c. Finlandia, sentencia 73053/01, 2006) $)^{74}$, pero cabe considerar que la extensión de todas las garantías que el artículo 6.1 de la CEDH exige en los procedimientos penales puros a los procedimientos administrativos sancionadores resultaría excesiva, debiendo modularse el ámbito y la intensidad de la protección del derecho al debido proceso en los procedimientos sancionadores en materia de defensa de la competencia (Andreangeli, 2010, pp. 225-227 y 233-234).

\section{Los derechos humanos de las personas jurí- dicas ("derechos humanos corporativos")}

La esencia de los derechos fundamentales es la protección de la vulnerabilidad de los seres humanos para asegurar a los individuos ciertas condiciones de dignidad y libertad básicas, principalmente frente a las injerencias y potenciales abusos del Estado. Sin embargo, la mayoría de los sujetos imputados (y sancionados) en los procedimientos sancionadores de defensa de la competencia ante el

70 Comprendiendo la garantía de imparcialidad, independencia, presunción de inocencia, la igualdad de armas, derecho de acceso pleno a las pruebas, derecho de audiencia, derecho a no declarar contra sí mismo y a obtener un pronunciamiento sin demoras justificadas.

71 Véase la sentencia del Tribunal Europeo de Derechos Humanos recaída en Ötzürk c. Alemania (Sentencia 8544/79, 1984).

72 Véase Huergo (2007, pp. 156-170).

73 Véanse los casos del Tribunal Europeo de Derechos Humanos Engel et al. c. Holanda (1976, párr. 81) y Marttinen c. Finlandia (2009, párr. 42).

74 La evolución de la noción de una «imputación criminal» ha apuntado a expandir gradualmente la responsabilidad del autor del hecho hacia casos que no pertenecen estrictamente a las categorías tradicionales del Derecho Penal, por ejemplo [...] el Derecho de la Competencia [...] [el cual] difiere de la parte esencial del Derecho Penal [de forma que] las garantías del autor del hecho no necesariamente se aplicarán con todo su rigor [traducción libre]. 
Indecopi son compañías mercantiles. Obviamente, la fragilidad y posible sufrimiento físico o psicológico de los individuos no caben en las personas jurídicas, sin cuerpo o identidad vulnerables.

No obstante, aunque los fundamentos morales y filosóficos de los derechos humanos no existan cuando los afectados por las intervenciones del Estado sean personas jurídicas ${ }^{75}$, progresivamente se ha asistido a una "humanización" gradual de las sociedades de capital ${ }^{76}$, que ha llevado a una progresiva extensión del reconocimiento de los derechos humanos a las personas jurídicas ${ }^{77}$.

Una evolución análoga se ha producido en Estados Unidos. Desde principios del siglo XIX el desarrollo de la jurisprudencia del Tribunal Supremo de Estados Unidos en materia de debido proceso (due process) a partir del artículo 3 de la Constitución de 17 septiembre de 1787 ha culminado en 1868 la decimocuarta enmienda a la Constitución Federal estadounidense (cláusula del debido proceso y sobre protección equitativa): “Ningún Estado podrá [...] privar a una persona de su vida, libertad o propiedad, sin un debido proceso legal; ni negar a persona alguna dentro de su jurisdicción la protección legal igualitaria". Aunque parece claro que, originariamente, los derechos emanados del artículo 3 de la Constitución norteamericana se ceñían en su reconocimiento a los individuos, ciudadanos y personas físicas, desde tempranas fechas se suscitó -aceptándose de manera progresiva- su extensión a las compañías mercantiles y personas jurídicas ${ }^{78}$. Paradójicamente, la consolidación de estos derechos constitucionales corporativos se anticipó en varias décadas a la de los derechos civiles de las minorías raciales ${ }^{79}$. La lucha contra los monopolios y los trusts a finales del siglo XIX (Standard Oil, American Tobacco Co.), criminalizando sus conductas y sus responsabili- dades a través de la Sherman Antitrust Act $^{80}$, dio lugar a la extensión de algunos derechos y libertades constitucionales (debido proceso, intimidad, no autoincriminación) a las compañías mercantiles, aunque la extensión no haya sido nunca idéntica (Winkler, 2018, p. 190).

Volviendo a Europa, de manera progresiva, la jurisprudencia del TEDH ha extendido el reconocimiento de derechos humanos a las personas jurídicas, mediante una interpretación dinámica y no formalista de la $\mathrm{CEDH}^{81}$. Esa extensión arranca con la sentencia Sunday Times c. Reino Unido (Sentencia 6538/74, 1979) y ha tenido lugar de manera particularizada a lo largo de diversos pronunciamientos. El reconocimiento de derechos fundamentales a las personas jurídicas no puede ser simétrico: estas carecen de muchos de los atributos humanos que sí justifican, en cambio, la protección de las personas físicas ${ }^{82}$. Así ha ocurrido, por ejemplo, sobre derecho a la privacidad del domicilio (CEDH, art. 8), materia en la que el TEDH ha estimado que el nivel de protección de las sedes de las personas jurídicas es inferior al del domicilio de las personas naturales (Société Colas Est. et. al. c. Francia, 2002) ${ }^{83}$.

Curiosamente, una de las áreas en las que la difusión de los derechos humanos corporativos en la jurisprudencia del TEDH ha sido más amplia ha sido en materia de procedimientos sancionadores por infracciones de defensa de la competencia ${ }^{84}$. Aunque esta creciente utilización por las compañías mercantiles de la vulneración de sus derechos humanos como argumento frente a las sanciones impuestas en procedimientos de investigación de conductas anticompetitivas es conceptualmente cuestionable (Sánchez Graells, 2014 , p. 269$)^{85}$, se trata de una realidad que es preciso aceptar ${ }^{86}$.

75 Véase, ampliamente, Ferrajoli (2009).

76 Véase Winfried (2012).

77 Para lo que sigue, véase Marcos y Sánchez Graells (2015).

78 Véanse Bank of US c. Deveaux (9 U.S. 61, 1809); Hope Insurance Co. c. Boardman (9 U.S. 57, 1809); Darmouth College c. Woodward (17 U.S. 528, 1819) y San Mateo County c. Southern Pacific Railroad Co., (116 U.S. 138, 1885).

79 Véase lo desarrollado por Winkler, quien describe la hábil y acaso controvertida contribución de varios abogados en la consecución de tal logro (Horace Binney y Daniek Webster en las dos primeras décadas del siglo XIX y, sobre todo, después de la aprobación de la $14^{\mathrm{a}}$ Enmienda, Roscoe Conkling) (2018).

80 Véase Winkler (2018).

81 Ampliamente, véase Emberland (2006).

82 Véase Adelstein (2013).

83 Véase Emberland (2003).

84 Véase Lande (2009).

85 A mi juicio, lo preferible y conceptualmente correcto (frente a una extensión indiscriminada y acrítica a las compañías mercantiles de los derechos humanos en el proceso penal) hubiera sido la construcción de un procedimiento antitrust justo, transparente y predecible, que reconociera las empresas garantías para proteger sus intereses frente a los posibles abusos de las autoridades de competencia.

86 Véase Díez Estella y Pérez Fernández (2018). 


\section{El principio de imparcialidad en los proce- dimientos sancionadores de defensa de la competencia: la separación de la instruc- ción y la resolución}

La atenuación de las diversas garantías que se contienen en el derecho al debido proceso del art. 6 $\mathrm{CEDH}$ en los procedimientos administrativos sancionadores (supra apartado §3.2), modulada aún más cuando los acusados son personas jurídicas (supra apartado §3.3), es el resultado de la jurisprudencia del TEDH, que se ha ido pronunciando al hilo de las reclamaciones planteadas en casos concretos.

La garantía de imparcialidad e independencia exige que exista separación entre el órgano acusador y el órgano resolutorio, sin que se confundan sus roles, de modo que pueda legítimamente dudarse de su imparcialidad (Kyprinaou c. Chipre, 2005, párrs. 118 y 127). La extensión de esa garantía de un proceso imparcial e independiente a los procedimientos administrativos sancionadores ha motivado varios pronunciamientos del TEDH, y el Tribunal ha dicho con claridad que la exigencia de

[q]ue las sanciones sean impuestas en primera instancia por un tribunal imparcial e independiente solo [opera] respecto de casos pertenecientes al núcleo duro del derecho penal, mientras en los demás casos admite que las sanciones puedan ser impuestas (en primera instancia) por autoridades administrativas o, más en general, por órganos no judiciales, siempre que la decisión de éstos sea sujeta a un control jurisdiccional posterior (Bertazzo, 2015, §2 in fine) $)^{87}$.

De modo que, por tanto, "el Tribunal admite una relajación de dichos principios y garantías ante la entidad de primera instancia, siempre que se permita la revisión de las decisiones de aquella ante un órgano judicial que tenga plena jurisdicción" (Bertazzo, 2015, §III.4.1) ${ }^{88}$.
Dicho brevemente, el TEDH traslada la garantía del debido proceso desde el procedimiento administrativo sancionador al proceso judicial posterior y esa garantía se cumple siempre que un juez pueda revisar los hechos y sanciones impuestas por la Administración, reemplazando la decisión de esta con su propia decisión (Moreno Trapiella, 2008, p. 326). Esta interpretación es plenamente coherente con el principio de separación de poderes. Aunque exista cierta discrecionalidad en el ejercicio de las potestades administrativas sancionadoras, la revisión judicial de ese ejercicio permitirá controlar cualquier eventual desviación de poder y corregir los errores manifiestos sobre la concurrencia de los elementos de la infracción en que pudiera haber incurrido la Administración.

En efecto, el TEDH ha concluido que respetan las exigencias del principio de imparcialidad los procedimientos sancionadores ante las autoridades administrativas únicas o integradas -como Indecopi- aunque no exista separación entre la instrucción y la resolución del expediente, siempre que exista la posibilidad de un recurso ante un órgano que reúna los requisitos previstos en el artículo 6.1 de la CEDH y que tenga plena jurisdicción para revisar el fondo del asunto, tanto los hechos como las cuestiones jurídicas ( $A$ Menarini Diagnostics SRL c. Italia, sentencia 43509/2008; Moreno Trapiella, 2008, p. 29). Así, para respetar las exigencias derivadas de la extensión del ámbito de aplicación del art. $6 \mathrm{CEDH}$ a los procedimientos administrativos sancionadores por infracciones del Derecho de la Competencia, si la organización interna adoptada por la autoridad no respeta el principio de imparcialidad, bastará con que las decisiones sancionadoras de las autoridades de competencia sean susceptibles de una revisión judicial por un órgano con jurisdicción bastante para anular la decisión si se identifican errores materiales de hecho o de derecho (Harris et al., 2009, pp. 228-229).

En el fondo, una regla análoga se extrae del recientemente aprobado por la ICN en el ICN Framework parte, los órganos jurisdiccionales que cumplan con los requisitos del párrafo 1 del Artículo 6, o que no cumplan con ello pero se sometan a un control posterior por un órgano judicial con poderes jurisdiccionales, que garanticen el cumplimiento del párrafo 1 del artículo 6 (1995, párr. 44) [traducción libre]. 
on Competition Agency Procedures, suscrito por el Indecopi ${ }^{89}$, conforme al cual:

Revisión independiente

[...] k) Ninguna agencia participante impondrá a una persona una prohibición, remedio o sanción en un procedimiento sancionador por infracción del derecho de la competencia aplicable sin que exista una oportunidad de que esa persona tenga derecho a la revisión por una entidad independiente e imparcial de decisión (p. ej., un juez, tribunal o corte de apelación) (ICN, 2019, p. 7) [traducción libre]

\section{E. Estándar de revisión en vía judicial}

Por tanto, la garantía de imparcialidad e independencia del órgano resolutorio de los procedimientos administrativos no exige, en todo caso, la separación del órgano instructor/acusador y del órgano resolutorio, siempre y cuando esa garantía se cumpla y exista en el control judicial posterior de sus decisiones ${ }^{90}$. Por tanto, para asegurar el respeto al debido proceso establecido en el artículo 6.1 de la CEDH, las decisiones de las autoridades administrativas que impongan sanciones deben ser susceptibles de recurso ante un órgano judicial con plena jurisdicción para pronunciarse sobre cualesquiera cuestiones de hecho o de derecho contenidas en la decisión que se impugna ${ }^{91}$. El juez debe tener potestad para hacer una apreciación de los hechos y pruebas empleados por la Administración en su decisión, revisando la existencia de infracción, pero también la proporcionalidad de la relación entre la infracción y la sanción, con posibilidad en su caso de modular o fijar la sanción adecuada (Moreno Trapiella, 2012, pp. 30-31).

No obstante, a diferencia de los procesos penales, la complejidad de las materias objeto de investigación en los procedimientos administrativos sancionadores y la experiencia y los conocimientos especializados que se requieren para la apreciación de la existencia de una infracción sancionable en materia de defensa de la competencia determinan que la intensidad del control pueda aminorarse, aceptándose por el TEDH que ese control sea limitado cuando concurran tales circunstancias y exista cierto margen de discrecionalidad administrativa ${ }^{92}$.

De nuevo, de manera análoga a lo que ocurría con los diferentes modelos o diseños de organización y estructura de las agencias de defensa de la competencia integradas, el alcance de la revisión judicial se presenta como una cuestión gradual, en la que en la intensidad y profundidad del control judicial depende del diseño y configuración de la autoridad de competencia y del procedimiento seguido en cada caso, de modo que "cuantas más salvaguardas y precauciones adopte la autoridad en la adopción de sus decisiones para evitar el sesgo condenatorio, menor será la necesidad de una revisión intensa (desde la perspectiva del principio de independencia)" (Ottow, 2015, p. 223).

En particular, dadas las particularidades de las prohibiciones de conductas anticompetitivas y su aplicación ${ }^{93}$, los conocimientos especializados ( $v$. gr., económicos o científicos), la complejidad del análisis requerido para su aplicación y el margen de discrecionalidad que otorgan a las autoridades de competencia se prevé que el control que ejerzan los tribunales sea restringido. Así, el estándar de revisión en sede judicial de las decisiones sancionadoras de las autoridades administrativas de la competencia no es necesario que comprenda una revisión total del fondo del asunto, aunque debe garantizar en todo caso que el órgano sancionador no ha actuado de manera ilegal, irrazonable o injusta (Weeks c. Reino Unido, 1987, párr. 69).

La jurisprudencia del TEDH permite fundamentar esta revisión judicial "más ligera" de las decisiones de naturaleza sancionadora de las autoridades administrativas si se cumplen ciertas condiciones. El órgano administrativo que adopta la decisión debe seguir un procedimiento que satisfaga debidamente las garantías del debido proceso, de modo que el diseño del procedimiento de aplicación sea apropiado (Bryan c. Reino Unido, 1995, párr. 47), y la decisión debe implicar "un ejercicio clásico de discreción administrativa", dicho en otras palabras, las cuestiones a decidir requieren un grado de co-

\footnotetext{
89 Véase supra nota 5.

90 Véase Schmautzer c. Austria (1995, párr. 34) y Bertazzo (2015, §III.4.4.).

91 Véanse A. Menarini Diagnostics SRL c. Italia (2011, párr. 59) y Segame S.A. c. Francia (2012, párr. 55). A tal efecto, la calidad y extensión de la revisión judicial son esenciales. En efecto, no existe "plena jurisdicción" si el órgano judicial no puede reformar y revisar la decisión de la administración impugnada. La anulación de la decisión y el reenvío a la administración para que se pronuncie de nuevo no parece suficiente (Moreno Trapiella, 2008, p. 328; Moreno Trapiella, 2012, 65-66)

92 Véanse Crompton c. Reino Unido (2009, párr. 73) y Bryan c. Reino Unido (1995, párr. 47).

93 Véase supra notas 14-17 y texto correspondiente
} 
nocimiento profesional o de experiencia y ejercicio de discreción administrativa en ejecución de objetivos públicos más generales (Tsfavo c. Reino Unido, 2006, párr. 46). En tales casos la revisión de la legalidad de la decisión será suficiente, y no sería necesaria una revisión del fondo del asunto (Zumbotel c. Austria, 1993, párr. 32), siempre y cuando la jurisdicción revisora pueda examinar todas las cuestiones de hecho y de derecho que en ella se contengan y efectivamente proporcionar un remedio para el recurrente en caso de éxito (Kingslev $c$. Reino Unido, 2002), incluida la posibilidad de anular la decisión y reenviar el caso a las autoridades de competencia para que adopten una nueva decisión (O’Boyle et al., 1995, pp. 229-232). En suma, no es suficiente con un mero control externo de la decisión, sino que es necesario que analice sus fundamentos y la adecuación y proporcionalidad de la sanción.

La información disponible permite constatar que en el Perú esa posibilidad existe ${ }^{94}$, y que la legislación vigente para la revisión de las decisiones del Indecopi en sede judicial cumpliría esos requisitos:

En primer lugar, un solo juez examinará la resolución administrativa. La decisión de este juez también podrá ser impugnada ante un tribunal colegiado. Finalmente, la decisión de este tribunal es apelable ante la Corte Suprema. Los tribunales podrán anular, dejar sin efecto y reformar las resoluciones administrativas. El Poder Judicial es plenamente competente para apreciar los hechos y el Derecho -excepto la Corte Suprema, que solo puede examinar las cuestiones jurídicas relacionadas con las decisiones judiciales. En este contexto, esto significa que un tribunal puede anular una resolución y devolverla al Indecopi; asimismo, un tribunal podrá sustituir la resolución dictada por el Indecopi (Organización para la Cooperación y el Desarrollo Económicos [OCDE] \& Banco Interamericano de Desarrollo [BID], 2018, p. 79) ${ }^{95}$.

\section{EVALUACIÓN DE LA ORGANIZACIÓN DEL IN- DECOPI A NIVEL COMPARADO}

En este apartado se analiza la organización seguida en otros sistemas de defensa de la competencia que presentan similitudes al diseño del Indecopi y en los que se ha cuestionado también su confor- midad con el principio de imparcialidad y las exigencias del debido proceso, dado que tampoco en ellos existe una separación absoluta entre instrucción y resolución de los procedimientos sancionadores. Tanto la Comisión Europea (infra apartado $\S 4.1)$, como la autoridad de defensa de la competencia italiana (infra apartado §4.2), presentan similitudes en su organización y procedimientos al modelo de Indecopi, habiéndose suscitado respecto de ambas algunas de las dudas sobre el respeto del derecho al debido proceso que ahora se vierten sobre el Indecopi (OCDE \& BID, 2018, p. 79).

\section{A. Comisión Europea}

En la Unión Europea, coexisten las autoridades nacionales de competencia y la Comisión Europea con competencias para la investigación y sanción de las prohibiciones de conductas anticompetitivas de los artículos 101 y 102 del Tratado de Funcionamiento de la UE (en adelante, TFUE).

Como es sabido, la Comisión Europea no es un órgano judicial; es una entidad administrativa supranacional que, en materia de procedimientos sancionadores de defensa de la competencia, se organiza como una agencia administrativa integrada. La incoación e instrucción de los expedientes corre a cargo de la DGCOM, que es también la que decide sobre la imposición de sanciones, aunque formalmente las decisiones sean adoptadas colectivamente por el colegio de comisarios ${ }^{96}$. El procedimiento es de carácter administrativo y se regula en el Reglamento $1 / 2003$, de 16 de diciembre de 2002 (desarrollado por el Reglamento 773/2004, de 7 de abril de 2004), que confiere amplias potestades a la Comisión para la investigación de las posibles infracciones de los artículos 101 y 102 del TFUE (requerimientos de información e inspecciones, con la eventual colaboración de las autoridades nacionales de defensa competencia de los Estados Miembros). Si la DGCOM tiene pruebas de que se ha producido una vulneración de los artículos 101 y 102 del TFUE formulará un pliego de cargos (statement of objections) en el que expone todas las pruebas y su valoración preliminar de las mismas (Reglamento 773/2004, art. 10). Los sujetos imputados tienen derecho a acceder al expediente administrativo y a contestar por escrito a los cargos contra ella, y también a una au-

95 Aunque ocasionalmente se haya censurado que los órganos judiciales suelan confirmar casi siempre sus decisiones (OECD \& BID, 2018, p. 146). Esta crítica contradice otras afirmaciones del propio informe OECD/BID, aunque pudiera deberse a una constatación anecdótica y no empírica del marco jurídico vigente (que, en verdad, es lo que cuenta, véase (Ibañez Colomo, 2018, p. 8).

96 Véase Yoo et al. (2019, p. 63). 
diencia oral del caso (Reglamento 773/2004, arts. 12 y 13$)^{97}$. Finalmente, si la Comisión entiende que las alegaciones de los imputados no alteran su valoración preliminar sobre la existencia de una infracción, la Comisión adopta una decisión que declara la comisión de la infracción e impone las sanciones previstas. La Decisión se redacta por los mismos funcionarios de la Dirección de Competencia que realizaron la investigación y elaboraron el pliego de cargos, aunque se consulta al servicio jurídico de la Comisión y a un Comité Asesor integrado por funcionarios de los Estados Miembros (OCDE, 2005, p. 40).

Las decisiones de la Comisión Europea que declaran la existencia de una infracción e imponen sanciones a los sujetos responsables de la misma son recurribles ante el Tribunal General de la Unión Europea (en adelante, el TGUE). El recurso ante el TGUE puede fundarse tanto en cuestiones relativas a los hechos como en la valoración jurídica efectuada por la Comisión (Reglamento 1/2003, arts. 261 y 263). La sentencia del TGUE que resuelva los recursos de apelación contra las decisiones de la Comisión Europea son susceptibles de un ulterior recurso, ahora sólo sobre la fundamentación jurídica, ante el Tribunal de Justicia de la Unión Europea (TJUE).

La falta de separación entre el órgano encargado de la instrucción y la resolución de los expedientes sancionadores en el procedimiento sancionador ante la Comisión Europea ha motivado que se haya dudado de si se respeta el derecho de los imputados al debido proceso y el principio de imparcialidad. Aunque el artículo 23.5 del Reglamento CE $1 / 2003$ establece que las sanciones impuestas por la Comisión "no tendrán carácter penal" (2002), esas multas puedan alcanzar elevados importes que las convierten en cuasi penales. Ello activaría la necesidad de respetar la protección de los acusados y sancionados prevista en el artículo 6 de la $\mathrm{CEDH}^{98}$. Por ello, en todo el procedimiento se han de respetar los derechos y garantías de los investigados, de conformidad con el artículo 47 de la Carta Europea de Derechos fundamentales ${ }^{99}$ y con la $\mathrm{CEDH}$. Sin embargo, el derecho al debido proceso en los procedimientos administrativos de defensa de la competencia ante la Comisión Europea no tiene el mismo alcance que la que se prevé en para los procedimientos penales. Está claro que la combinación en el mismo órgano de las funciones de instrucción/investigación y resolución impiden que pueda considerarse de un órgano independiente e imparcial, pero eso no hace que sea incompatible con el art. 6.1 de la CEDH (véase supra apartado $\S 3)$. Es verdad que existe el riesgo de que la Comisión (rectius sus funcionarios) sean víctimas de un sesgo acusador, que podría conducir a errores en las sanciones impuestas por la autoridad (Wouter, 2004, p. 212). Este sesgo cognitivo supondría la inclinación de la Comisión a concluir mediante decisiones sancionadoras los expedientes incoados y las investigaciones iniciadas (Slater et al., 2009, p. 129). Desde otra perspectiva, pero ineludiblemente vinculado a lo anterior, existiría un posible prejuicio de retrospectiva (hindisight bias), que dificultaría la revisión por los funcionarios de la Comisión de las posiciones seguidas en los pliegos de cargos ya enviados a los acusados por la Comisión (Wils, 2004, pp. 215-216) ${ }^{100}$.

Por ello, en coherencia con la jurisprudencia del TEDH, si las infracciones de las prohibiciones de conductas anticompetitivas se castigan con sanciones "cuasi penales" -en el sentido de dicho precepto- y se encarga a autoridades administrativas su aplicación, el respeto del derecho al debido proceso se entiende asegurado si los sujetos sancionados tienen derecho a recurrir la decisión de las autoridades administrativas ante un órgano con jurisdicción plena y que cumpla las garantías del art. 6.1 de la $\mathrm{CEDH}^{101}$.

Aunque la ética profesional del personal de la Comisión y la credibilidad de la institución pueden

$97 \quad$ La audiencia oral se desarrolla ante un oficial de la comisión (hearing officer), que no pertenece a la Dirección General de Competencia. Véase la Decisión del Presidente de la Comisión Europea del 13 de octubre de 2011, relativa a la función y el mandato del consejero auditor en determinados procedimientos de competencia (DOUE L 275, 2011).

98 Véase Slater et al. (2009, pp. 103-121).

99 Que reza:

toda persona cuyos derechos y libertades garantizados por el Derecho de la Unión hayan sido violados tiene derecho a la tutela judicial efectiva respetando las condiciones establecidas en el presente artículo. Toda persona tiene derecho a que su causa sea oída equitativa y públicamente y dentro de un plazo razonable por un juez independiente e imparcial, establecido previamente por la ley. Toda persona podrá hacerse aconsejar, defender y representar. Se prestará asistencia jurídica gratuita a quienes no dispongan de recursos suficientes siempre y cuando dicha asistencia sea necesaria para garantizar la efectividad del acceso a la justicia (Carta de los Derechos de la Unión Europea, 2016, art. 47) [el énfasis es nuestro].

100 Id. últ. 130. Aunque se trata de un fenómeno que puede ser recurrente en esta materia, véase recientemente Leslie (2018).

101 Véase Ibañez Cólomo (2018, pp. 7-8) y Wils (2004, p. 209). 
ayudar a evitar los mencionados errores ${ }^{102}$, se han introducido otras medidas internas de control para intentar prevenir los errores, corrigiendo el posible sesgo acusador y la miopía retrospectiva. Así, se prevén la revisión de los pliegos por equipos distintos de funcionarios dentro de la Dirección de Competencia, la participación del equipo del Economista jefe cuando fuera pertinente, y la intervención con un papel primordial del oficial encargado de audiencias previas (hearing officer) y el comité asesor (OCDE, 2005, pp. 39-40 y 62-63). Sin embargo, no es posible excluir en todo caso que ocurran errores ${ }^{103}$, y por eso debe entenderse que es esencial el reconocimiento del derecho de los sancionados a instar la revisión judicial de las decisiones de la Comisión ante el TGUE y el TJUE ${ }^{104}$.

Como antes hemos visto (supra apartado §3.5) lo relevante entonces será el alcance de la revisión judicial $^{105}$, y en varias sentencias del Tribunal de Justicia de la UE ha aclarado que, en particular, en el caso de cárteles ese control judicial es pleno e ilimitado ${ }^{106}$ :

Por lo que se refiere al control de legalidad, el Tribunal de Justicia ha declarado que, si bien en los ámbitos que exijan apreciaciones económicas complejas, la Comisión dispone de cierto margen de apreciación en materia económica, ello no implica que el juez de la Unión deba abstenerse de controlar la interpretación que haga la Comisión de datos de carácter económico. En efecto, el juez de la Unión no sólo debe verificar la exactitud material de los elementos probatorios invocados, su fiabilidad y su coherencia, sino también comprobar si tales elementos constituyen el conjunto de datos pertinentes que deben tomarse en consideración para apreciar una situación compleja y si son adecuados para sostener las conclusiones que se deducen de los mismos (2011, párr. 94) $)^{107}$.

\section{B. Autorità Garante della Concorrenza e del Mercato (AGCM)}

En Italia la investigación y sanción de las infracciones de las prohibiciones de prácticas anticompetitivas es competencia de la Autoritá Garante della Concorrenza e del Mercato (en adelante, AGCM ${ }^{108}$. Se trata de una agencia de defensa de la competencia integrada ante la que se tramitan los procedimientos administrativos sancionadores antitrust. La AGCM se rige por un órgano colegial compuesto de un presidente y cuatro miembros, que adoptan decisiones por mayoría (Ley 287, 1990, art. 10.2). Son elegidos por el presidente de la Cámara de Diputados y del Senado de la República entre personas de reconocido prestigio e independencia y son nombrados por un período de 7 años, no renovables.

La decisión de investigar determinadas conductas y de incoar un expediente sancionador le corresponde al consejo de la AGCM (formado por el presidente y los cuatro miembros) (Ley 287, 1998, art. 6.1.) $)^{109}$ que, además, desempeña un rol primordial durante la instrucción -siendo además el competente para autorizar inspecciones o prácticas de pruebas periciales (Decreto 217/98, arts. 10 y 11)-. Aunque la investigación de las posibles infracciones corre a cargo de la Dirección General de Instrucción (Direzione Generale Istruttoria) de la AGCM, dependiente de la Secretaría General de la AGCM, corresponde al consejo de la AGCM permitir el envío del pliego de cargos y propuesta de resolución a los investigados: "El consejo, tras comprobar que las propuestas formuladas por las unidades de investigación en relación con las pruebas obtenidas no son manifiestamente infundadas, autoriza la comunicación de las conclusiones preliminares alcanzadas a las empresas" (Decreto 217/98, art. 14.1). También ante el consejo de la AGM se efectúa la vista oral del

102 Véase Wils (2004, pp. 217-218).

103 Véase Wils, (2004, pp. 219-220) y Van der Woude (2019).Sobre una muestra, de la praxis de la Federal Trade Commission en materia de fusiones entre 1950 y 1988, véase Coate y Kleit (1998).

104 Véase Wils (2004, p. 220). Igualmente, refiriéndose a las decisiones tanto de la autoridad española como europea, Ortiz y Lamadrid señalan "en la medida en que las decisiones [...] son en todo caso susceptibles de impugnación ante los órganos jurisdiccionales, su compatibilidad formal con las necesarias garantías de imparcialidad y de protección de los derechos de defensa no plantea problemas" (2009, pp. 282-283).

105 Cfr. MacGregor y Gecic (2012, pp. 430-431) y Nagy (2016, pp. 232-238).

106 Véanse SSTJUE de 8 de diciembre de 2011 (sala 2a) KME (tubos industriales) C-272/09P (ECLI:EU:C:2011:810); Chalkor C-286/10P ( ECLI:EU:C:2011:815) y KME Germany AG et al. C-389/10 (ECLI:EU:C:2011:816).

107 Finalmente, el Tribunal de Justicia también ha aclarado que así se respetan las exigencias del derecho a un debido proceso (2011, párr. 106).

108 Véase Siragusa et al. (2010).

109 Art. 6.1 (avvio dell'istruttoria) del Decreto Presidencial 217 de 30 de abril de 1998 (reglamento en materia de procedimientos de instrucción competencia de la AGCM. Esta norma detalla la regulación de los procedimientos ante la AGCM, las potestades de investigación y los derechos de las partes. Se aplica también la normativa general en materia de procedimiento administrativo contenida en la Ley 241 de 8 de agosto de 1990. 
procedimiento (Decreto 217/98, art. 14.5), y concluida la instrucción, es el consejo el que adopta la decisión final (Decreto 217/98, art. 14.9). Las decisiones de la AGCM son recurribles al Tribunal Administrativo Regional de Lacio (Ley 287/1990, art. 33.1), y luego las sentencias del T.A.R. de Lacio son apelables ante el Consejo de Estado (Consiglio di Stato) ${ }^{110}$.

La somera descripción anterior pone de relieve que el consejo de la AGCM interviene tanto en la instrucción como en la resolución del expediente, sin que pueda hablarse de una separación de funciones y de su atribución a distintos órganos (aun así, no es infrecuente que el consejo discrepe del parecer de la Dirección General de Instrucción). No obstante, lo anterior, de acuerdo con la jurisprudencia del TEDH sobre el art. 6.1 CEDH (examinada supra apartado §3), que está vigente también en Italia, se entiende que el derecho al debido proceso queda garantizado por la existencia de un ulterior control judicial pleno sobre las decisiones de la AGCM. En efecto, aunque el T.A.R. de Lacio no ejerce un control de plena jurisdicción sobre las cuestiones jurídicas, para respetar la discrecionalidad de la AGCM, si lo efectúa sobre las cuestiones fácticas y sobre la aplicación de las sanciones, pudiendo anular la decisión de la AGCM. Además, el Consejo de Estado sí que puede controlar la valoración jurídica, con lo que se garantizaría el derecho al debido proceso de las partes ${ }^{111}$.

En particular, la antes citada sentencia del TEDH A Menarini Diagnostics SRL c. Italia, (sentencia $43509 / 2008,2011$ ) se refiere a un caso que tuvo lugar ante la AGCM, cuya relevancia hace pertinente una referencia detallada en este momento. La empresa A. Menarini Diagnostics S.R.L. fue sancionada por la AGCM con una multa de 6 millones de euros por vulnerar la prohibición de prácticas anticompetitivas mediante la participación en un cártel que fijó los precios y se repartió el mercado de los equipos para la diagnosis de la diabetes en Italia ${ }^{112}$. Menarini acudió al TEDH alegando que el T.A.R. de Lacio que había decidido su recurso contra la decisión de la AGCM no había ejercido una jurisdicción plena. Tras considerar que los procedimientos de aplicación de las prohibiciones anti- trust caen bajo el ámbito de aplicación del art. 6 de la CEDH debiendo respetarse el derecho al debido proceso, el TEDH afirmó que esa norma no se opone a una decisión de primera instancia por un órgano administrativo, siempre y cuando exista posibilidad de recurrir ante un órgano judicial con jurisdicción plena para revisar el asunto. El órgano judicial revisor debe tener potestad para anular la decisión administrativa, revisando tanto su fundamentación fáctica como jurídica ( $A$ Meranini Diagnostics SRL c. Italia, 2011, párrs. 38-44 y 5859). Finalmente, el TEDH dictaminó que en el caso concreto los tribunales administrativos italianos habían ejercido jurisdicción plena en la revisión del asunto (2011, párrs. 60-69).

\section{CONCLUSIONES}

La aplicación pública de las prohibiciones de conductas anticompetitivas en el Perú se realiza por el Indecopi a través de un procedimiento administrativo que prevé diversas fases. En el procedimiento participan, en primera instancia, la STCLC y la CLC, encargándose la primera de la investigación e instrucción del expediente sancionador y la segunda de su resolución. Está contemplado apoyo y asistencia de la STCLC a la CLC, de modo que no existe una separación o aislamiento absoluto entre estos dos órganos ni, por ende, entre la instrucción y resolución del procedimiento. En segunda instancia administrativa, la decisión de la Comisión puede recurrirse a la Sala Especializada de Libre Competencia del Tribunal del Indecopi. Después, las decisiones adoptadas por el Tribunal del Indecopi pueden recurrirse ante la jurisdicción contencioso-administrativa que tiene potestad plena para revisar las decisiones administrativas tanto en las cuestiones de hecho como en las cuestiones de derecho, pudiendo anular la decisión si se apreciasen errores de valoración o en la tramitación del expediente sancionador. Se trata de un diseño y una organización eficientes, que tienen en cuenta los recursos, objetivos y limitaciones existentes, sin que la imparcialidad sea el único, ni el principal criterio a seguir. Además, las sucesivas fases administrativas del procedimiento sancionador antitrust ante el Indecopi y la ulterior revisión judicial se presentan adecuados para prevenir y corregir los riesgos

110 Excepcionalmente estas decisiones podrían recurrirse al Tribunal Supremo (Corte di Cassazione) en casos tasados (Codice Procedura Civile, art. 396).

111 Véanse Chieppa \& Giovagnoli (2018, pp. 351-353) y Giosis (2017).

112 Decisión AGCM de 30 de abril de 2003. el T.A.R. de Lazio rechazó el recurso mediante sentencia de 3 de diciembre de 2003 que se limitó a controlar la legitimidad del acto administrativo adoptado por la AGCM, dado que su competencia es limitada para revisar la valoración jurídica discrecional efectuada por la AGCM (aunque el TAR tendría, en su caso, plena jurisdicción tanto para revisar la valoración de los hechos por la AGCM como para revisar la aplicación de la sanción). También el Consejo de Estado rechazó el recurso contra la sentencia del T.A.R. mediante sentencia de 16 de marzo de 2006. Finalmente, la sentencia del Consejo de Estado fue confirmada por el Tribunal Supremo a través de sentencia de 17 de marzo de 2008. 
de prejuicios y errores en la aplicación de las prohibiciones por parte del Indecopi y, en particular, el posible sesgo acusatorio y de sobre aplicación (falsos negativos o errores tipo 1).

Por otra parte, existe una tendencia progresiva de extender los derechos reconocidos a los acusados en los procesos penales a los imputados en los procedimientos sancionadores administrativos. La jurisprudencia del TEDH es una buena ilustración de esa tendencia en la que es preciso apuntar que la asimilación de esas garantías no es simétrica y menos cuando los imputados en los procedimientos sancionadores son compañías mercantiles y personas jurídicas, debiendo examinarse y modularse en su proyección al caso concreto. En particular, el derecho al debido proceso y la garantía de imparcialidad del órgano que adopta las decisiones e imponga las sanciones exige que en los procesos penales exista separación entre la instrucción y la resolución.

En cambio, en el caso de los procedimientos administradores sancionadores el TEDH entiende que si esa separación no existe en la fase administrativa de instrucción y resolución del expediente sancionador, la garantía de imparcialidad se verá asegurada si existe el derecho a recurrir la decisión sancionadora ante un órgano judicial con plena jurisdicción para revisar tanto los elementos fácticos como la valoración jurídica efectuada por la autoridad administrativa, que pueden llevar incluso a la anulación de la decisión. La legislación vigente en el Perú reconoce el derecho de recurso en vía judicial de los sancionados por el Indecopi por la infracción de las prohibiciones de conductas anticompetitivas (una vez agotada la vía de recurso administrativo ante el Tribunal del Indecopi), con lo que se salvaguarda el derecho al debido proceso.

\section{REFERENCIAS}

Adelstein, R. (2013). Fimrs as persons. Cahiers $d^{\prime}$ Economie Politique, (65), 161-182.

American Bar Association [ABA] (29 de abril de 2019). Assessment of Global Competition Agency Implementation of ABA Best Practices for Antitrust Procedure. https://www.americanbar.org/content/dam/aba/administrative/ antitrust_law/sal-procedural-transparency-2019-04-29.pdf

Andreangelli, A. (2010). Between Economic Freedom and Effective Competition Enforcement: The impact of Antitrust Remedies provided by the Modernization Regulation. Competition Law Review, 6(2), 225-257.
(2012). Competition law and human rights: striking a balance between business freedom and regulatory intervention. En I. Lianos \& D. Sokol (eds.), The Global Limits of Competition Law. Standford University Press.

Baker, J. B. (2015). Taking the error out of 'error cost' analysis: What's wrong with the antitrust's right. Antitrust Law Journal, 80(1), 1-38. https://www.antitrustinstitute.org/wpcontent/uploads/2018/08/Error-Cost-BakerALJ-80-1-FINAL-PDF-1.pdf

Becker, G. S. (1968). Crime and Punishment: an economic approach. Journal of Political Economy, 76(2), 169-217.

Bertazzo, S. (2015). El Derecho Administrativo sancionador a la luz del Convenio Europeo de los Derechos Humanos. Revista General de Derecho Administrativo, (39).

Breit, W. \& Elzinga K. G. (1974). The Instruments of Antitrust Enforcement. Emory Law Journal, (23), 943-961.

Chieppa, R. \& Giovagnoli, R. (2018). Manuale di Diritto Amministrativo (4ta ed.). Giuffrè Francis Lefebvre.

Coate, M. B., \& Kleit, A. N. (1998). Does it Matter that the Prosecutor is Also the Judge? The Administrative Complaint Process at the Federal Trade Commission. Managerial Decision Economics, (19), 1-11.

Cooper, J. C. \& Kovacic. W. E. (2012). Behavioral economics: implication for regulatory behavior. Journal of Regulatory Economics, (41), 41-58.

Crane, D. A. (2011). The Institutional Structure of Antitrust Enforcement. Oxford University Press.

Davidson, K. (2005). Creating Effective Competition Institutions: Ideas for Transitional Economies. Asian Pacific Law \& Policy Journal, 6(1), 71-129. http://blog.hawaii.edu/aplpj/ files/2011/11/APLPJ_06.1_davidson.pdf

Delgado, J. \& Mariscal, E. (2014). Integrating Regulatory and Antitrust Powers: Does it work? Case studies from Spain and Mexico. Competition Policy International, 10(1), 135-159. https://ssrn.com/abstract $=2403047$

Devlin, A. \& Jacobs, M. (2010). Antitrust Error. William \& Mary Law Review, 52(1), 75-132. https://scholarship.law.wm.edu/wmlr/vol52/ iss $1 / 3$ 
Diez Canseco Núñez, L. J. (1997). Función regulatoria, promoción de la competencia y legislación antimonopólica. THËMIS-Revista de Derecho, (36), 39-63. http://revistas.pucp.edu.pe/index. php/themis/article/view/11725/12286

Duke, A. (2015). Public Enforcement. En Duns, J., Duke, A., \& Sweeney, B. (Eds.), Comparative Competition Law (pp. 271-300). Edward Elgar Publishing Limited.

Easterbrook, F. H. (1984). The Limits of Antitrust. Texas Law Review, 63(1). https://chicagounbound.uchicago.edu/cgi/viewcontent.cgi?artic le=2152\&context=journal_articles

Emberland, M. (2006). The Human Rights of Companies. Exploring the Structure of ECHR protection. Oxford University Press.

(2013). Protection Against Unwarranted Searches and Seizures of Corporate Premises under article 8 of the European Convention of Human Rights: The Colas Eat SA v. France Approach. Michigan Journal of International Law, (25), 77-116.

Ergas, H. (2009). Error and Design: Economics in (and Some Economics of) the Australian Competition Tribunal. Agenda: A Journal of Policy Analysis and Reform, 16(3), 71-91.

Ferrajoli, L. (2009). Los fundamentos de los derechos fundamentales (4ta ed.). Trotta.

Forrester, I. S. (2009). Due process in EU competition cases: A distinguished institution with flawed procedures. European Law Review, (34), 817-843.

Fox, E. M., \& Trebilcock, M. J. (2012) Introduction. En Fox, E.M., \& Trebilcock, M.J. (Eds.), The Design of Competition Law Institutions, Global Norms, Local Choices (pp. xi-lxi). Oxford University Press.

Fox, E. M. (2010). Antitrust and Institutions: Design and Change. Loyola University Chicago Law Journal, 41(3), 473-488. https://lawecommons.luc.edu/cgi/viewcontent.cgi?referer $=\& \mathrm{~h}$ ttpsredir $=1 \&$ article $=1065 \&$ context=luclj

Gómez Apac, H. (2009). El rol instructor de la Secretaría Técnica de la Comisión de Defensa de la Libre Competencia. Revista de Derecho Administrativo, (7), 472-483.

Harris, D., O'Boyle, M., Bates, E., \& Buckley, C. (2009). Harris, O'Boyle \& Wabrick: Law of the
European Convention on Human Rights (2da ed.). Oxford University Press.

Huego, A. (2007). Las sanciones administrativas. lustel Madrid.

(2019). Las sanciones administrativas en el marco del law enforcement. En D. Zegarra (ed.), La Proyección del Derecho Administrativo Peruano. Estudios por el Centenario de la Facultad de Derecho de la PUCP (515-539). Palestra.

Ibáñez Colomo, P. (2018). The Shaping of EU Competition Law. Cambridge University Press.

International Competition Network [ICN] (2019a). ICN Framework on Competition Agency Procedures. https://www.internationalcompetitionnetwork.org/wp-content/uploads/2019/04/ ICN_CAP.pdf

(2019b). ICN CAP Participants (as for August 2019). https://www.internationalcompetitionnetwork.org/wp-content/uploads/2019/08/ CAPparticipants.pdf

Kaplow, L. (1992). Rules versus standards: an economic analysis. Duke Law Journal, 42, 557-629. http://nrs.harvard.edu/urn-3:HUL.InstRepos:10611784

Kaplow, L., \& Shavell, S. (2002). Economic Analysis of Law. En Auerbach, A.J. \& Feldstein, M. (Eds.), Handbook of Public Economics (Vol. III, pp. 1665-1784). http://www.law.harvard.edu/ faculty/shavell/pdf/99_Economic_analysis_ of_law.pdf

Komesar, N. (2010). Stranger in a Strange Land: An Outsider's View of Antitrust and the Courts. Loyola U. Chicago L. J., (41), 443-453.

Kovacic, W. E., Hollman, H. H. \& Grant, P. (2011). How does your competition agency measure up? European Competition Journal, 7(1), 25-45. https://www.jonesday. com/files/Publication/6bf2d85c-ea824c6e-8d77-977afbf26ab7/Presentation/ PublicationAttachment/169372fa-b7ab-452983fd-43207901b1b9/competitionagency.pdf

Kovacic, W. E. \& Hyman, D. A. (2012). Competition Agency Design: What's on the Menu? European Competition Journal, 8(3), 527-538. https://doi.org/10.5235/ECJ.8.3.527

(2013). Competition Agencies with Complex Policy Portfolios: Divide or Conquer? (Chicago, 28 Oct. 2011) [Entrada de blog]. Concurrences: 
Antitrust Publications \& Events. https://www. concurrences.com/en/review/issues/no-12013/conferences/competition-agencies-withcomplex-policy-portfolios-divide-or-conquerchicago

Lande, R. H. (2009). Quick-Somebody call Amnesty International! Intel Says EU Antitrust Violated Human Rights. Federal Trade Commission: Watch, 746(9).

Lawrence, W. (21 de noviembre de 2019). Why isn't "Deterrence" Included in the Measurements of Antitrust "Enforcement"? [Entrada de blog]. CPI Competition Policy International. https://www.competitionpolicyinternational. com/why-isnt-deterrence-included-in-themeasurements-of-antitrust-enforcement/

Leslie, C. (2018). Hindsight Bias in Antitrust Law. Vanderbilt Law Review, 71(5), 1527-1591.

López Torralba, V. (2005). Breve estudio en torno al Procedimiento sancionador y sus garantías. Revista jurídica de la Comunidad de Madrid, (22), 181-244.

MacGregor, A., \& Gecic, B. (2012). Due Proces in EU Competition Cases Following the Introduction of the New Best Practices Guidelines on Antitrust Proceedings. Journal of European Competition Law \& Practice, 3(5), 425-438.

Marcos Fernández, F. (2017). Independencia de las autoridades de defensa de la competencia en España. Revista de Derecho de la Competencia y Distribución, (21).

Marcos Fernández, F., \& Sánchez Graells, A. (2015). En contra del reconocimiento de "derechos humanos corporativos" en los procedimientos sancionadores en materia de defensa de la competencia. En J. Guillén Caramés \& M. Cuerdo Mir (dirs.), Estudios sobre la potestad sancionadora en Derecho de la Competencia. Civitas. Thompson-Reuters.

Marsden, P. (2009). Checks and balances: EU competition law and the rule of law. Competition Law International, (1), 25-29.

Moore, D. A, Tanlu, L., \& Bazerman, M. H. (2010). Conflict of interest and the intrusion of bias. Judgement and Decision Making, 5(1), 37-53.

Moreno Trapiella, P. (2008). El control judicial de las sanciones administrativas en el convenio europeo de derechos humanos. Documentación Administrativa, (280-281), 323-258.
(2012). Convenio Europeo de Derechos Humanos y contencioso administrativo español. El caso específico del control judicial de las sanciones. Marcial Pons.

Nagy, C. I. (2016). EU Competition law's fair trial revolution: much ado about nothing? European Competition Law, 37(6), 232-238.

Nieto, A. (2012). Derecho administrativo sancionador (5ta ed.). Tecnos.

O’Brien, P. (14 de noviembre de 2018). Procedural Fairness: Convergence in Process [Entrada de blog]. CPI Competition Policy International. https://www.competitionpolicyinternational.com/procedural-fairness-convergencein-process/

Ochoa Cardich, C. (1996). Límites de la potestad sancionadora del Indecopi y las garantías del administrado en los procedimientos administrativos del Derecho de la Competencia. Ius et Veritas, (13), 185-198.

Organización para la Cooperación y el Desarrollo Económico [OCDE] (2018). Exámenes Inter-Pares de la OCDE y el BID sobre el Derecho y Política de Competencia: Perú. https://www.oecd. org/daf/competition/PERU-Peer-Reviews-ofCompetition-Law-and-Policy-SP-2018.pdf

Ortiz, L, \& Lamadrid, A. (2009). El procedimiento sancionador y sus garantías. En S. Martínez \& A. Petitbó (dirs), Los acuerdos horizontales entre empresas (pp. 279-307). Marcial Pons.

Ottow, A. (2015). Market and Competition Authorities: Good Agency Principles. Oxford University Press.

Patrón, C. (2008). Aciertos, divergencias y desatinos de la nueva Ley de Represión de Conductas Anticompetitivas. Ius et Veritas, (36), 122- 144.

Polinsky, A. M. \& Shavell, S. (2007). The Optimal Structure of Law Enforcement. En Polinsky, A.M. \& Shavell, S. (Eds), Handbook of Law and Economics (Vol. I, pp. 404-454). Elsevier. http:// www.law.harvard.edu/faculty/shavell/pdf/07Polinsky-Shavell-Public\%20Enforcement\%20 of\%20Law-Hdbk\%20LE.pdf

Rallo, A. (2014). La Comisión Nacional de los Mercados y la Competencia: Los reparos de las instituciones europeas sobre la independencia del regulador. Teoría y Realidad ConstitucionalUNED, (34), 193-234. 
Sánchez Graells, A. (2014). The EU's Accession to the ECHR and Due Process Right in UE Competition Law Matters: Nothing under the Sun. En V. Kosta, N. Skourotakis \& V. Tzevelekos (eds.), The Accesion of the UE to the ECHR (255-270). Hart.

Shapiro, I., \& Mc Carthy, C. W. (2011). Are Federal Agencies the Sole Judges of Their Own Authority? Regulation, (34), 4-5.

Shavell, S. (1993). The Optimal Structure of Law Enforcement. Journal of Law \& Economics, (36), 255-287. http://www.law.harvard.edu/ faculty/shavell/pdf/36_J_law_Econ_255.pdf

(1995). The appeals process as a means of error correction. Journal of Legal Studies, (24), $379-426$.

Sigurasa, M., Beretta, M., \& Bay, M. (2010). Competition law in Italy: The first 20 years of law practice. En Competition Laws Outside the United States (2da ed.). ABA.

Slater, D., Thomas, S., \& Waelbroeck, D. (2009). Competition Law Proceedings before the European Commission and the Right to a fair trial: No need to reform. European Competition Journal, (5).

Stucchi López-Raygada, P. (2008). El nuevo diseño del control de conductas para la defensa de la libre competencia: Apuntes sobre el Decreto Legislativo 1034 - Ley de Represión de Conductas Anticompetitivas (LRCA). THEMISRevista de Derecho, (56), 309-330. http://revistas.pucp.edu.pe/index.php/themis/article/ view/9217/9628

(2011). Apuntes sobre la relevancia constitucional del mandato funcional del Indecopi. $A d-$ vocatus, (23), 47-60.

Stucchi López-Raygada, P. \& Ballón Estacio, F. (2017). Síntesis de la defensa de la libre competencia en el Perú. Contenido y aplicación del Decreto Legislativo $N^{\circ} 1034$. Ley de Represión de Conductas Anticompetitivas (LRCA). Revista de Derecho de la Universidad de Piura, (18). https://pe.lejister.com/pop.php?optio $\mathrm{n}=$ articulo\&Hash=70b2c9d5abea8e6155376 $2 f 767997206$

Suay Rincón, J. (1990). La discutible vigencia de los principios de imparcialidad y contradicción en el procedimiento administrativo sancionador. $R A P,(123), 153-184$.

Trebilcock, M. J. \& labocucci, E. M. (2002). Designing Competition Law Institutions. World Com- petition, 25(3), 361-394. https://ssrn.com/abstract $=2064918$

(2010). Designing Competition Law Institutions: Values, Structure, and Mandate. Loyola University of Chicago Law Journal, (41), 455471. https://www.luc.edu/media/lucedu/law/ students/publications/llj/pdfs/trebilcock_iacobucci.pdf

Valencia Dongo, A. (2017). Juntos y revueltos: diseño institucional y Garantías de un debido proceso. Bullard Falla Ezcurrat. https://www. bullardabogados.pe/publications/wp-content/ uploads/2017/11/Juntos-y-revueltos_AVD.pdf

Vermeule, A. (2014). The Constitution at Risk. Cambridge University Press.

Waldron, J. (2012). 'Partly Laws Common to All Mankind': Foreign Law in American Courts. Yale University Press.

White, L. (2019). Why isn't 'Deterrence' Included in the Measurements of Antitrust 'Enforcement'. CPI Antitrust Chronicle.

Wils, P. J. (2004). The combination of the Investigative and Procedural Function and the Adjudicative Function in EC Antitrust Enforcement: A Legal and Economic Analysis. World Competition, (27), 201-224.

Winkler, A. (2018). We The Corporations. How American Businesses won their civil rights. Liveright.

Yoo, C. (23 de septiembre de 2019). Due Process in International Antitrust Enforcement: An Idea Whose Time Has come [Entrada de blog]. CPI Competition Policy International. https:// www.competitionpolicyinternational.com/ due-process-in-international-antitrust-enforcement-an-idea-whose-time-has-come/

\section{LEGISLACIÓN, JURISPRUDENCIA Y OTROS DOCU- MENTOS LEGALES}

Albert \& Le Compte c. Bélgica, 5 E.H.R.R. 533 (1983).

A Menarini Dignastics SRL c. Italia (2011).

Bank of US v. Deveaux, 9 U.S. 61 (1809).

Bendenoun c. Francia, 18 E.H.R.R. 54 (1994).

Bryan c. Reino Unido, 21 E.H.R.R. 342 (1995). 
Case C-272/09 P, KME Germany y otros v. Comm'n, 2011 E.C.R. I-12789.

Case C-386/10 P, Chalkor AE Eperxergasias Metallon v. Comm'n, 2011 E.C.R. I-13085.

Case C.389/10 P, KMG Germany y otros v. Comm'n, 2011 E.C.R. I-13125.

Chrompton c. Reino Unido, E.C.H.R. 27 (2009).

Darmouth College v. Woodward, 17 U.S. 528 (1819).

De Cubber c. Bélgica, E.C.R.R. 14 (1984).

Decreto Legislativo 1033, Decreto Legislativo que aprueba la ley de organización y funciones del Instituto Nacional de Defensa de la Competencia y de la Protección de la Propiedad Intelectual - Indecopi, Diario Oficial El Peruano, de 24 de junio de 2008 (Perú).

Decreto Supremo 004-2019-JUS, Decreto Supremo que aprueba el Texto Único Ordenado de la Ley № 27444, Ley del Procedimiento Administrativo General, Diario Oficial El Peruano, de 25 de enero de 2019 (Perú).

Decreto Supremo 030-2019-PCM, Decreto Supremo que aprueba el Texto Único Ordenado de la Ley de Represión de Conductas Anticompetitivas aprobada por el Decreto Legislativo $N^{\circ} 1034$, Diario Oficial El Peruano, de 18 de febrero de 2019 (Perú).

Decreto Supremo 344-2018-EF, Decreto Supremo que aprueba el Reglamente de la Ley $\mathrm{N}^{\circ} 30225$, Diario Oficial El Peruano, de 31 de diciembre de 2018 (Perú).

Engel et al. c. Países Bajos, 1 E.H.R.R. 647 (1976).

Gradinger c. Austria (1995).

Hope Insurance Co. v. Boadman, 9 U.S. 57 (1809).

Janosevic c. Suecia, 38 Eur. Ct. H.R. 473 (2004).
Jussila c. Finlandia, 2006 E.C.H.R. 996.

Kingsley c. Reino Unido (2002).

Kyprinaou c. Chipre, 2005 Eur. Ct. H.R. 873.

Levages Prestation Services c. France (1996).

Ley de Creación de la Comisión Nacional de los Mercados y la Competencia (B.O.E. 2013, 3) (Esp.).

Ley de Defensa de la Competencia (B.O.E. 2007, 15) (Esp.).

Ley del Régimen Jurídico de las Administraciones Públicas y del Procedimiento Administrativo Común (B.O.E. 1992, 30) (Esp.).

Marttinen c. Finlandia, 2009 Eur. Ct. H.R. 658.

Menarini Diagnostics SRL c. Italia, 2011 Eur. Ct. H.R.

Öztürk c. Alemania, 6 E.H.R.R. 409 (1984).

Reglamento del Consejo relativo a la aplicación de las normas sobre competencia previstas en los artículos 81 y 82 del Tratado (B.O.E, 2003, 1) (Esp).

San Mateo County v. Southern Pacific Railroad Co., 116 U.S. 138 (1885).

Segame S.A. c. Francia (2012).

Société Colas Est. et. al. c. Francia, 2002 Eur. Ct. H.R. 418.

Sociéte Stenuit c. Francia, 232 E.H.R.R. (ser. A) (1992).

Sunday Times c. Reino Unido, 2 E.H.R.R. 245 (1979).

Tsfayo c. Reino Unido, E.C.H.R. 14 (2006).

Zumbotel c. Austria, E.C.H.R. 41 (1993). 